\title{
Electrical lithosphere beneath the Kaapvaal craton, southern Africa
}

\author{
Rob L. Evans, ${ }^{1}$ Alan G. Jones, ${ }^{2}$ Xavier Garcia, ${ }^{3}$ Mark Muller, ${ }^{2}$ Mark Hamilton,,${ }^{2,4}$ \\ Shane Evans, ${ }^{5,6}$ C. J. S. Fourie, ${ }^{7,8}$ Jessica Spratt, ${ }^{2,9}$ Susan Webb, ${ }^{10}$ Hielke Jelsma, ${ }^{5}$ \\ and Dave Hutchins ${ }^{11}$
}

Received 23 July 2010; revised 16 December 2010; accepted 7 February 2011; published 20 April 2011.

[1] A regional-scale magnetotelluric (MT) experiment across the southern African Kaapvaal craton and surrounding terranes, called the Southern African Magnetotelluric Experiment (SAMTEX), has revealed complex structure in the lithospheric mantle. Large variations in maximum resistivity at depths to $200-250 \mathrm{~km}$ relate directly to age and tectonic provenance of surface structures. Within the central portions of the Kaapvaal craton are regions of resistive lithosphere about $230 \mathrm{~km}$ thick, in agreement with estimates from xenolith thermobarometry and seismic surface wave tomography, but thinner than inferred from seismic body wave tomography. The MT data are unable to discriminate between a completely dry or slightly "damp" (a few hundred parts per million of water) structure within the transitional region at the base of the lithosphere. However, the structure of the uppermost $\sim 150 \mathrm{~km}$ of lithosphere is consistent with enhanced, but still low, conductivities reported for hydrous olivine and orthopyroxene at levels of water reported for Kaapvaal xenoliths. The electrical lithosphere around the Kimberley and Premier diamond mines is thinner than the maximum craton thickness found between Kimberley and Johannesburg/Pretoria. The mantle beneath the Bushveld Complex is highly conducting at depths around $60 \mathrm{~km}$. Possible explanations for these high conductivities include graphite or sulphide and/or iron metals associated with the Bushveld magmatic event. We suggest that one of these conductive phases (most likely melt-related sulphides) could electrically connect iron-rich garnets in a garnet-rich eclogitic composition associated with a relict subduction slab.

Citation: Evans, R. L., et al. (2011), Electrical lithosphere beneath the Kaapvaal craton, southern Africa, J. Geophys. Res., 116, B04105, doi:10.1029/2010JB007883.

\section{Introduction}

[2] Archean cratons form the ancient and stable cores of continents, and provide a window on the early Earth and the processes that were occurring under what are inferred to be hotter thermal conditions than at present. How these cratons

\footnotetext{
${ }^{1}$ Department of Geology and Geophysics, Woods Hole Oceanographic Institution, Woods Hole, Massachusetts, USA.

${ }^{2}$ Dublin Institute for Advanced Studies, Dublin, Ireland.

${ }^{3}$ Barcelona Center for Subsurface Imaging, Unitat de Tecnologia Marina, Barcelona, Spain.

${ }^{4}$ Now at EMGS, Trondheim, Norway.

${ }^{5}$ De Beers Group Services, Southdale, South Africa.

${ }^{6}$ Now at Moombarriga Geoscience, West Perth, Western Australia, Australia.

${ }^{7}$ Council for Geoscience, Pretoria, South Africa.

${ }^{8}$ Now at Environmental, Water and Earth Science Department, Tshwane University of Technology, Pretoria, South Africa.

${ }^{9}$ Now at Natural Resources Canada, Ottawa, Ontario, Canada.

${ }^{10}$ School of Geosciences, University of Witwatersrand, Wits, South Africa.

${ }^{11}$ Geological Survey of Namibia, Windhoek, Namibia.
}

Copyright 2011 by the American Geophysical Union. 0148-0227/11/2010JB007883 formed, particularly the apparent cogeneses of their crust and mantle roots, remains a first-order problem of global significance if we are to construct a coherent model of Earth's evolution from its earliest formation to the present day. Central to our understanding of continental evolution is providing a better understanding of how the mantle participated in the growth and stabilization of ancient cratons.

[3] One of the distinguishing features of Archean cratons is a thick lithospheric root that extends deep $(>200 \mathrm{~km})$ into the mantle. Lithospheric thickness can be estimated in several ways, including directly from geophysical measurements and also by inference from xenolith-based geothermobarometry [Eaton et al., 2009]. Electrical resistivity within the mantle is controlled by temperature and composition, as well as by the presence of interconnected conducting phases, such as fluids or metallic conductors [Jones, 1999]. Thus, resistivity lends itself to the identification of key strata and their boundaries, both vertically and laterally. The base of the lithosphere, or the lithosphere-asthenosphere boundary (LAB), is one of these important tectonic boundaries. Eaton et al. [2009] discuss in depth the nature of the LAB determined by different methods, and the implications 
of a range of mantle compositions and rheologies on $\mathrm{LAB}$ structure. Of particular importance is the amount of water present in the lithospheric and uppermost asthenospheric mantle, as the presence of water dramatically impacts on many physical parameters, particularly mantle viscosity. If the lithosphere is entirely dry to its base and the uppermost asthenosphere wet, then models predict a broad region of deformation within the asthenosphere immediately beneath the cratonic root. In such models, there can be significant discrepancies between an LAB defined on the basis of strain rate and on thermal parameters or their proxies (velocities and electrical conductivity). If there is water within a lithospheric transition zone between a completely dry and rigid uppermost lithosphere and the asthenosphere, then the possibility arises that under appropriate thermal conditions parts of this wet transition zone may break off and sink into the asthenosphere, potentially creating significant topography in the LAB [Lee et al., 2005]. Variations in thickness along with the thermal structure and water content of the lithosphere and asthenosphere can be constrained by the use of magnetotelluric (MT) methods [e.g., Jones, 1999; Korja, 2007]. In addition, as suggested by Tozer [1979, 1981], electrical conductivity is a physical observable that can give insight into viscosity. Indeed, Tozer [1981] and now Karato [2006] suggest that observing electrical conductivity is the best method for sensing viscosity and water content.

[4] We have collected an extensive MT data set across southern Africa (Figure 1), in an experiment called the Southern African Magnetotelluric Experiment (SAMTEX), with the aim of determining the geometry of structures as expressed by electrical conductivity variations in the crust, lithospheric mantle and underlying asthenosphere. The overarching objectives are to elucidate the secular variation of lithospheric formation and deformation processes from the Meso-Archean to the present by comparing lithospheric geometries found with those of other cratons and younger regions. The total number of stations exceeds 740 over an area in excess of one million square kilometers, and the total length of the profiles is more than $15,000 \mathrm{~km}$, with coverage extending across the Kaapvaal craton through the surrounding mobile belts and into adjacent cratons to the north and west. The conductivity models derived from these data provide an alternative and complementary view of lithospheric structure to those provided by seismic or geochemical approaches. The extensive areal data coverage allows us to examine structural boundaries, both laterally and with depth. Boundaries defined on the basis of electrical resistivity can be compared to those used to define the cratons and mobile belts (derived mainly from surface geology and aeromagnetic data). Lithospheric structure can also be compared with occurrences of diamondiferous kimberlites in an attempt to unravel the connection between the deep lithosphere and diamond provenance. In this paper we discuss regional maps of maximum resistivity which are a representation of the raw data and focus on 2-D inversions of a $\sim 1500 \mathrm{~km}$ profile crossing the Kaapvaal craton.

\section{Background: Southern African Lithospheric Structure}

[5] The Kaapvaal craton in southern Africa is an archetypical Archean craton which covers an area of around $1.6 \times$
$10^{6} \mathrm{~km}^{2}$ and forms the nucleus around which the southern part of the African continent has amalgamated. The craton formed over the interval 3.7-2.6 Ga, and much of the crust and mantle from that time remains intact [de Wit et al., 1992]. The region has been extensively studied, with a large seismic experiment [James et al., 2001; Fouch et al., 2004], called the Southern African Seismic Experiment (SASE), spanning the Kaapvaal and Zimbabwe cratons and the Limpopo mobile belt which welds them together. These seismic studies complement comprehensive geochemical data from diamond inclusions [Shirey et al., 2002, 2004] and xenoliths [e.g., James et al., 2004] from across the Kaapvaal.

[6] The Kaapvaal craton is seen to have a thick lithospheric root in both its geophysical and geochemical characteristics. It is a commonly held belief that cratonic roots represent mantle that has undergone high degrees of depletion through melting, and this belief is supported both by geochemistry [e.g., Banas et al., 2009], and observations of higher seismic velocity [e.g., James et al., 2001; Fouch et al., 2004]. One of the ways used to estimate lithospheric thickness is through the analysis of xenolith samples, albeit with a highly biased and nonuniform sampling both spatially and in depth [Artemieva, 2009a]. Xenoliths provide estimates of the base of lithosphere in two ways: (1) they can provide an estimate of the depth to the base of the "chemically depleted" lithosphere on the basis of the geochemistry of the xenolith minerals (the so-called Chemical Boundary Layer), and (2) they can estimate the depth to the "thermal" base of the lithosphere on the basis of a xenolith constrained P-T geotherm and its intersection with the mantle adiabat (the thermal boundary layer). In most cases, the estimate of the thermal lithospheric thickness is a more appropriate comparison with MT and seismic derived thicknesses. A suite of xenolith samples from both the Kaapvaal and Zimbabwe cratons suggests a lithospheric thickness between 200 and $250 \mathrm{~km}$ with a preferred (thermal) thickness estimate of $224 \mathrm{~km}$ [Rudnick and Nyblade, 1999]. Eaton et al. [2009] provide a summary of xenolith data [e.g., Boyd and Nixon, 1978; Smith and Boyd, 1989; Grütter et al., 2006] from the Lesotho and Kimberley kimberlite clusters that show a range of "thermal" lithospheric thicknesses from 185 to $215 \mathrm{~km}$. Some of the xenolith suites show evidence of thermal and/or chemical disturbance, presumably within a transition zone between lithosphere and fully adiabatic mantle and due to the thermal and metasomatic processes associated with kimberlite melt generation.

[7] These geochemical lithospheric thickness estimates are far smaller than those inferred from seismic tomography. An extensive tomography experiment shows high-velocity roots extending to depths of $250 \mathrm{~km}$, and in places to as deep as $300 \mathrm{~km}$ or greater [James et al., 2001; Fouch et al., 2004], although the velocity gradient at the base of the lithosphere is fairly gentle, making a definitive assessment of lithospheric thickness difficult. Tomography also has to deal with competing effects on velocity of composition and temperature [e.g., Artemieva, 2009b; Jones et al., 2009a]. Thick roots are seen to lie beneath the Kaapvaal and Zimbabwe cratons, with markedly thinner lithosphere beneath the surrounding Proterozoic terranes. In contrast, tomographic modeling of dispersion curves from fundamental mode Rayleigh wave phase velocities suggest a 


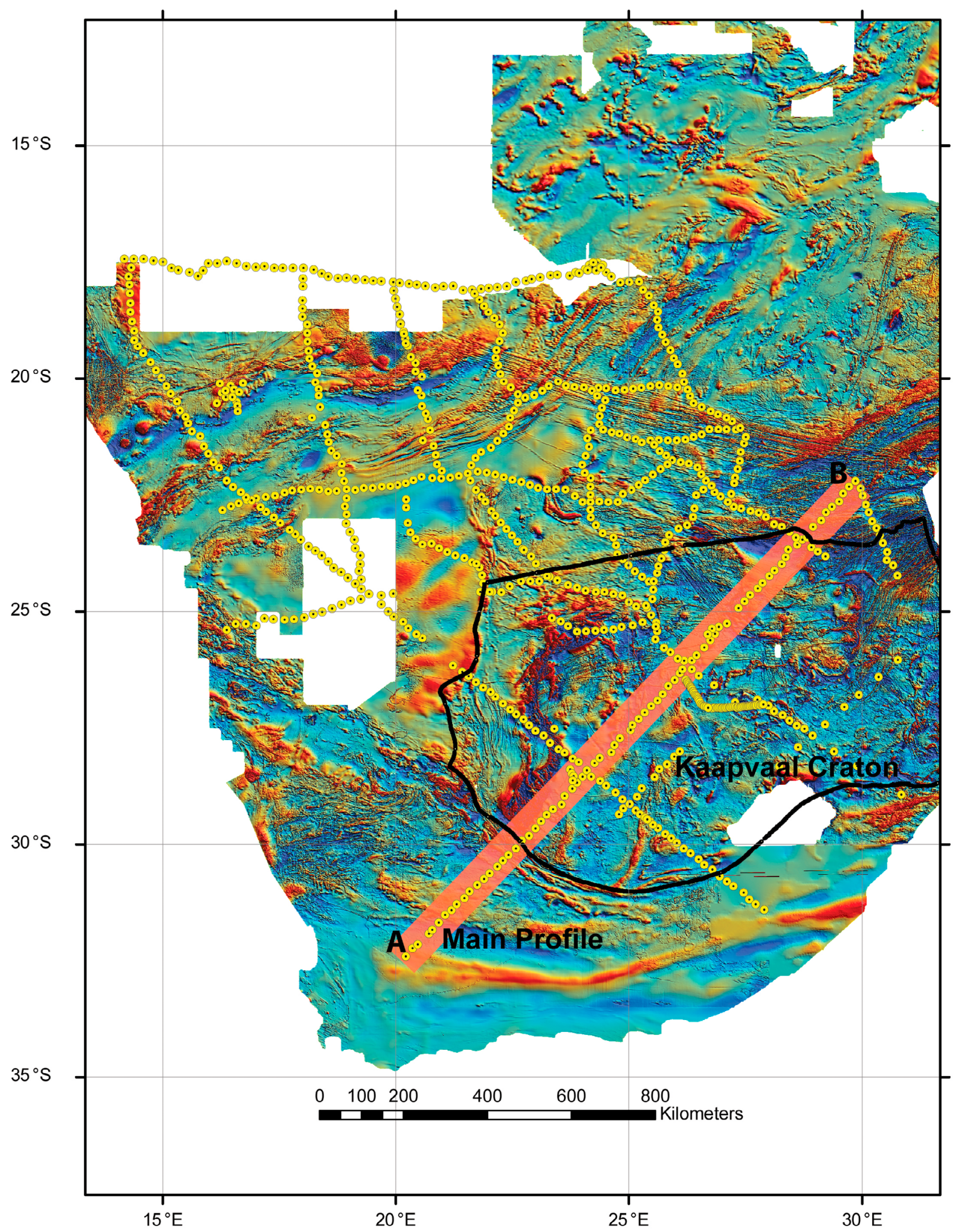

Figure 1. A map of southern Africa aeromagnetic data with the MT stations completed during the SAMTEX experiment shown (yellow dots). The main profile considered in this paper is labeled (A and B). The outline of the Kaapvaal craton, based on surface geology and geophysics [Webb, 2009], is shown as the black line. 
lithospheric thickness of $\sim 180+/-20 \mathrm{~km}$, with the central and southern parts of the craton underlain by an asthenosphere of reduced shear wave velocity $(4.5 \mathrm{~km} / \mathrm{s}$; see $L i$ and Burke [2006] and Yang et al. [2008]). Conflicting, to some extent, with this result is an analysis of two-station Rayleigh wave velocities, carefully picked to encompass only the undisturbed regions of the Kaapvaal, and in which subsurface structure is laterally averaged over the distance between station pairs [Larson et al., 2006]. Inversion of these velocities shows a reduction in $\mathrm{Vs}$ below $180 \mathrm{~km}$, but no values less than $4.55 \mathrm{~km} / \mathrm{s}$ were required to explain the data. The observed gradual decrease in Vs with depth is consistent with a cratonic geotherm [James et al., 2004] and does not require any thermal (or other) perturbation. Finally, $S$ wave receiver function (SRF) analyses show a seismic discontinuity, interpreted as the lithosphere-asthenosphere boundary, at $160 \mathrm{~km}$ underlain by a low-velocity zone with a maximum thickness of $90 \mathrm{~km}$ [Hansen et al., 2009]. The $S$ receiver function data permit a wide range of velocities within the low-velocity zone, but there is no requirement for any significant thermal anomaly. That an impedance boundary likely exists at $160 \mathrm{~km}$ is not in question, but its interpretation is. Given that diamonds are present in kimberlites that erupted only $65 \mathrm{Myr}$ ago, and that the graphitediamond stability field lies at about $160 \mathrm{~km}$, it is impossible for the $160 \mathrm{~km}$ boundary to be the base of the lithosphere as has been suggested [e.g., Rychert and Shearer, 2009]. These recent results are also at variance with previous SRF studies by Kumar et al. [2007], who presented lithospheric thicknesses of $>200$ to $260 \mathrm{~km}$ for the Kaapvaal craton, and by Wittlinger and Farra [2007], who concluded that the lithosphere was even thicker, to $300 \mathrm{~km}$.

[8] An important clue to Archean lithospheric formation is the presence of diamonds in erupted kimberlites [e.g., Boyd and Gurney, 1986]. While diamonds, including those from the Kaapvaal craton, are typically Archean and Proterozoic in age [Shirey et al., 2004], the kimberlite pipes which bring the diamonds to the surface erupted mostly in the Cretaceous [Ben-Ismail et al., 2001], and in the Slave craton in northern Canada there are kimberlites that date as recently as the Eocene $(55-50 \mathrm{Ma})$. (Note that here we are adopting the generally held view that dating diamond inclusions can reliably give the age of the diamond.) This suggests that diamonds were emplaced within the deep lithospheric mantle as the craton stabilized [e.g., Richardson et al., 1984; Boyd et al., 1985; Boyd and Gurney, 1986], and that mantle conditions since the Archean have not favored either diamond formation or storage (or both). Diamonds from the Kaapvaal region show two modal ages: 3.2-3.3 and $2.9 \mathrm{Ga}$ [Richardson et al., 2001], although Proterozoic diamonds have also been recovered. This has been suggested to show at least a two-stage process for the formation of the Kaapvaal craton, with the older diamonds associated with the formation of the eastern Kaapvaal and the younger suite associated with a subduction-related event as the western and eastern parts of the Kaapvaal craton were sutured along the modern-day Colesburg lineament, which is expressed by a north-south trending surface magnetic anomaly [Richardson et al., 2001]. There is further evidence for subduction-related accretion along the western boundary of the Kaapvaal craton and also along the western edge of the Zimbabwe craton, which is welded to the north of the Kaapvaal craton by the Limpopo Mobile Belt [Shirey et al., 2004]. Seismic SKS analyses have been used to infer the stages of craton amalgamation with an arcuate pattern of splitting polarizations suggestive of several bands of accretion running to the west of the Colesburg magnetic lineament, and then turning more east-west through the Bushveld Complex. These regions are interpreted to be orogenic bands that were welded onto an existing craton within which there is no evidence for lithospheric seismic anisotropy [Silver et al., 2004].

[9] Shirey et al. [2002] show that trends in lithospheric mantle seismic velocity are correlated with compositions of silicate inclusions in diamonds taken from kimberlite pipes across the craton. The lithospheric mantle has two bands of high velocity separated by a broad WNW-trending band of lower-velocity mantle [James et al., 2001]. Silicate inclusions in diamonds from the slow region show primarily eclogitic parageneses and younger ages. Seismic structure mirrors inclusion chemistry, suggesting that diamonds have been stored in mantle with these different velocity structures. Seismic velocity is dependent on temperature, but a 1.2 Ga cold cratonic geotherm is found (defined by mantle xenolith P-T arrays) beneath the Premier kimberlite pipe in an area characterized by slow velocities, which suggests that chemical composition may be a more important factor in controlling velocity than temperature. Slow regions of the mantle may be higher in basaltic components ( $\mathrm{Fe}, \mathrm{Ca}, \mathrm{Cpx}$ ), or metasomatizing fluids that hydrated and altered the host peridotite [Shirey et al., 2002, 2004].

\section{What Is the Electrical Lithosphere and How Does It Relate to Other Measures of Lithospheric Thickness?}

[10] The definition of the lithosphere is hotly debated [Anderson, 1995; Artemieva, 2009b; Eaton et al., 2009]. Given our observation method, we define the lithosphere as the uppermost region of the Earth which falls on a conductive geotherm. Implicit in this definition is that this uppermost region is not participating in mantle convection (hence the conductive geotherm) and, as such, is behaving as a semipermanent, rigid feature. It has been argued that the isotherm corresponding to the base of this layer $\left(\sim 1300^{\circ} \mathrm{C}\right)$ is significantly hotter than the limit of elastic behavior $\left(\sim 650^{\circ} \mathrm{C}\right)$ [Anderson, 1995], resulting in a discrepancy between the elastic (the Mechanical Boundary Layer) and thermal lithospheric thickness. Lee et al. [2005] note that the transition zone between the truly conductively cooling lithospheric mantle and the adiabatic mantle can be quite broad, and they therefore split the thermal boundary layer (TBL) into two components: an uppermost chemically depleted [Niu et al., 2004], dry and strong [Hirth et al., 2000] chemical boundary layer (CBL); and a transitional convective sublayer (CSL), the thickness of which depends on the thermal state of the craton. The presence of water, either in the lithospheric mantle or in the asthenosphere, has a large effect on the mantle viscosity [e.g., Tozer, 1979, 1981; Hirth and Kohlstedt, 1996], and in turn on mantle strain rates needed to accommodate plate motion. 
[11] The electrical conductivity of the asthenosphere will depend on the adiabatic temperature and the composition of the mantle. If the mantle is dry, then conductivities will be in the range of $10^{-2} \mathrm{~S} / \mathrm{m}$ with perhaps a factor of 2-3 uncertainty reflecting uncertainty in the adiabat. If the mantle is wet, then laboratory data suggest an enhancement in conductivity, by up to an order of magnitude [Wang et al., 2006; Yoshino et al., 2006; Poe et al., 2010]. More controversial is whether the presence of water can result in an anisotropic conductivity with the highest conductivity parallel to any shear induced flow in the mantle (see further discussion below). The presence of melt in the asthenosphere would similarly increase the conductivity, potentially by several orders of magnitude if carbonatite melt is present, even at very small melt fractions [Gaillard et al., 2008]. The choice of $10^{-2} \mathrm{~S} / \mathrm{m}$ to denote the onset of asthenosphere seems a conservative one; this choice allows us to define the top of the asthenosphere, but does not necessarily define what is above. The LAB, based on a definition that the lithosphere be rigid and nonconvecting, is likely shallower than estimates based on this definition. The choice does, however, place an upper bound on lithospheric thickness from electrical measurements.

\section{Experiment}

[12] The MT data collected consists of a mix of broadband MT (BBMT) soundings (periods from $\sim 0.002 \mathrm{~s}$ to $\sim 6000 \mathrm{~s}$ ), augmented with soundings made by long period (LMT) instruments ( $20 \mathrm{~s}$ to $\sim 10,000 \mathrm{~s}$ or greater) to enhance the depth of penetration. The total number of stations in the SAMTEX project exceeds 740 . The total length of the profiles is of the order of $15,000 \mathrm{~km}$, with a BBMT station spacing of nominally $20 \mathrm{~km}$, and an LMT spacing of $60 \mathrm{~km}$ (every third BBMT site along the main profile across the Kaapvaal). LMT stations were deployed for up to 3 weeks while BBMT sites were occupied for 2 nights of acquisition. While the initial goal of the experiment was to survey the Kaapvaal craton, coverage has been expanded onto the surrounding terranes through partnering with additional academic, government and industrial partners, providing valuable information on the variability of lithospheric structure in southern Africa (see Jones et al. [2009b] for a discussion).

[13] The electric and magnetic field time series data were processed into MT response functions using standard robust and controlled leverage techniques [Jones and Joedicke, 1984; Chave and Thomson, 2004; Egbert, 1997] (see also methods 6, 7, and 8 in the work of Jones et al. [1989]). The LMT stations used remote references that were far removed as, along the main profile considered in this paper, all 26 LMT sites were deployed simultaneously. Logistical considerations meant that the BBMT data were remote referenced with one of the stations out at the same time, which gave a maximum separation of $60-80 \mathrm{~km}$. In most cases this separation distance is sufficient, although both BBMT and LMT data around Kimberley suffered from the effects of DC electric trains and DC electric mine noise. The resulting response functions were merged where necessary (i.e., where LMT and BBMT data were collected at the same sites). The data have also undergone extensive decomposition and strike analyses [Hamilton et al., 2006; Hamilton, 2008].

\section{Maximum Conductivity Maps and the Surface Definition of Cratons and Mobile Belts}

[14] Modeling of all the data in a single 3-D subcontinental-scale model is a long-term goal of our project, however, this is a significant undertaking that is currently beyond the limits of all but the largest clusters of computers and for those with a lot of patience. In order to appreciate the information contained in the data we have constructed a variety of maps based on first-order information contained in the response functions [Jones et al., 2009b]. The maps are made by estimating the periods required to penetrate to the projected map depth using the Niblett-Bostick (NB) transform from apparent resistivity and phase as a function of period to layer resistivity as a function of depth [Niblett and Sayn-Wittgenstein, 1960; Jones, 1983a, 1983c; Vozoff, 1986; Jones et al., 2009b]. There are very different depths of penetration along the profile: the southernmost sections of data, for example, are underlain by conductive sediments and so longer periods are required to penetrate the mantle than in the more resistive cratonic section around Kimberley [Hamilton, 2008]. The resultant maps are simply representations of the actual resistivity distribution; they are not models constructed through either a forward data-fitting exercise or application of a formal inversion of the data for the resistivity model. Furthermore, the approximations used assume a 1-D anisotropic Earth structure, when the largescale structure is clearly $3-\mathrm{D}$. Despite these limitations, the maps provide a way to synthesize a significant amount of information from a large and complex data set in an easy-toread uniform manner. We verify the major features in the maps through use of formal 2-D inversion with models for the main Kaapvaal profile presented below and those from a roughly perpendicular profile running just to the south of Kimberley in the work of Muller et al. [2009].

[15] The maps show the maximum resistivity for each site at a given depth obtained by rotating the apparent resistivity and phase data through $180^{\circ}$, deriving the NB transformed resistivity-depth data, and determining the largest value of resistivity at the particular depth of interest. This maximum resistivity is only affected by significant conductive bodies and is less affected by distortion effects, and therefore results in conservative maps. A map of maximum conductivity at $200 \mathrm{~km}$ depth shows considerable variability in structure across the region (Figure 2; see also Jones et al. [2009b]). Within the confines (defined by crustal exposure and aeromagnetics) of the Kaapvaal craton, resistivity is generally very high, even at $200 \mathrm{~km}$ depth. Not surprisingly though, the area of highly resistive mantle root is smaller than the surface boundaries of the Kaapvaal. There are, however, departures from this, most notably beneath the Bushveld magmatic complex, which has highly conductive crust and upper mantle. The Kheis Belt is more conductive at depths around $200 \mathrm{~km}$ than is the central Kaapvaal. This feature is a thin skinned Proterozoic thrust/fold belt that is inferred to be emplaced on top of the Archean Ventersdorp supracrustal succession, with the mantle-lithosphere below the Kheis Belt also most likely Archean in age [de Wit et al., 


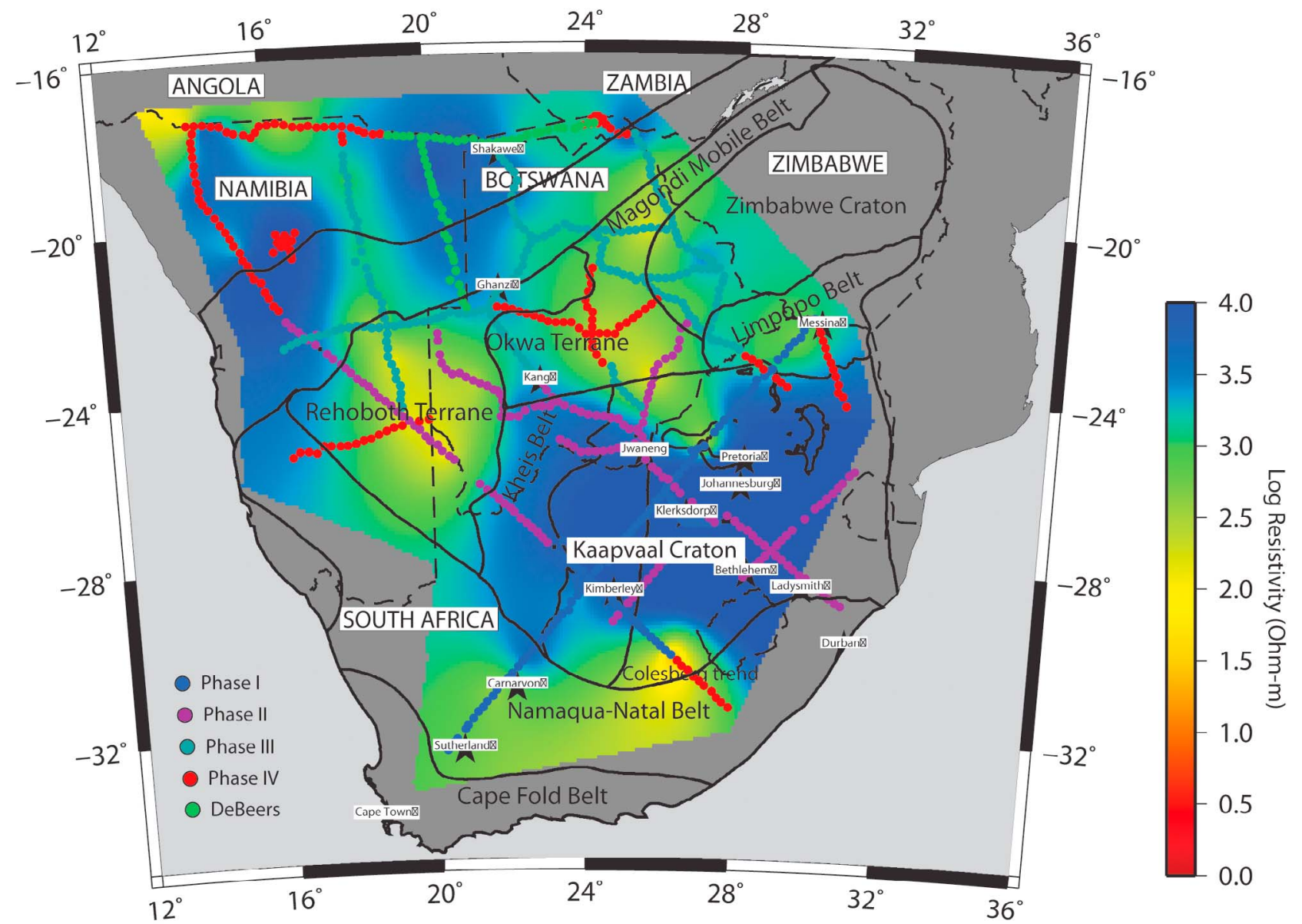

Figure 2. A map of maximum resistivity at a depth of $200 \mathrm{~km}$ for all data collected during the SAMTEX experiment.

1992]. Largely on the basis of the evidence in seismic reflection imaging, Tinker et al. [2004] and de Wit and Tinker [2004] infer the presence of the 2.7 Ga Ventersdorp Supergroup volcano-sedimentary succession at depth (in the upper to midcrust) across the entire Kimberley Block of the Kaapvaal craton, including below the Kheis Fold Belt, and extending to the edge of the craton defined by the Kalahari Lineament. Presumably the Ventersdorp volcanosedimentary succession was erupted and deposited on lithosphere that had already stabilized. These maps compare favorably with the results of seismic imaging of the region [see Jones et al., 2009b, Figures 8 and 9].

\section{Inversion of Data Across the Kaapvaal Craton}

[16] The inversion of the main profile across the Kaapvaal craton has been performed using the code of Rodi and Mackie [2001], as implemented in the WinGLink software package and also in a stand-alone code that solves for anisotropic conductivity structures [Evans et al., 2005; Baba et al., 2006]. Both inversions are regularized and seek minimum structure $2-\mathrm{D}$ resistivity models. The trade-off between closely fitting the data and obtaining a smooth model is controlled by a Tikhonov regularization (weighting) parameter $\tau$. We have run a series of inversions emphasizing different parts of the data as well as exploring model space by systematically varying the $\tau$ parameter. This allows us to look at the features that are required by the data and examine how they change as the data are fit to increasing levels of closeness. The distortion-corrected data, determined using the McNeice and Jones [2001] strike code, have been derived in a direction such that the modes are aligned appropriately parallel and perpendicular with the strike of the profile. The mode parallel to the profile is the so-called Transverse Magnetic (TM) mode of induction, and the model perpendicular to the profile is the Transverse Electric (TE) mode. We note that Hamilton et al. [2006] showed a maximum conductivity direction in the mantle that is roughly parallel to the profile direction. If this were the true electrical strike (there is a 90 degree ambiguity in strike direction) then we would be unable to carry out a 2-D inversion of the data given the acquisition geometry. However, the electrical strike seen is almost certainly the result of a combination of effects. These effects include the large-scale heterogeneity in resistivity structure associated with the presence of the cratonic root in which a 2- or 3-D resistor-conductor contact in the mantle influences the current patterns creating the false impression that the electrical structure is anisotropic.

[17] The possibility also arises that the asthenospheric mantle has an electrical anisotropy, as suggested by the directions of highest conductivity seen in data that probe the 


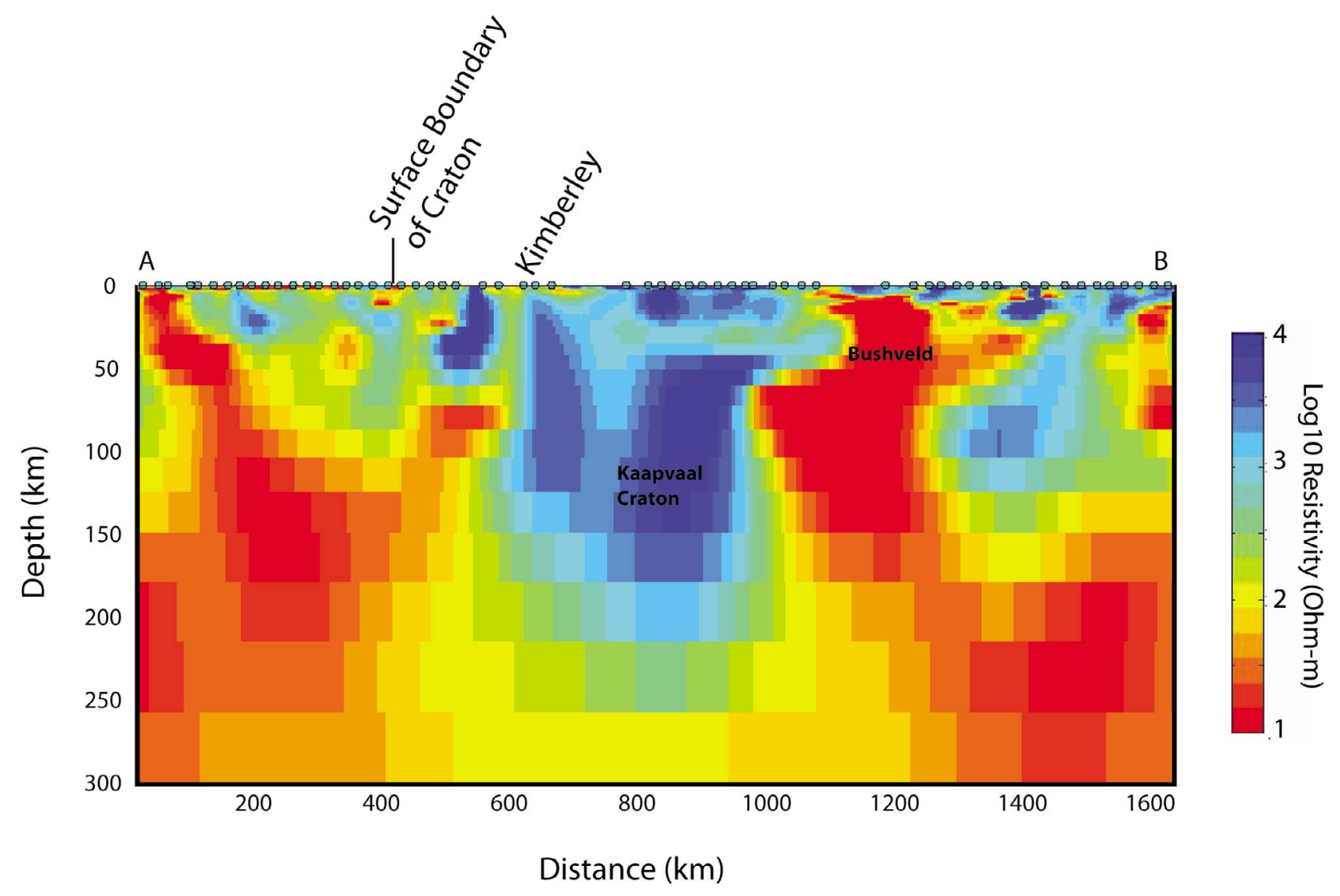

Figure 3. An isotropic inversion model of the main SAMTEX profile across the Kaapvaal craton and surrounding terranes. Points A and B are as shown in Figure 1. Labeled are the resistive root of the Kaapvaal craton and the highly conductive mantle beneath the Bushveld Complex. Because of the large variations in structure, the depths of penetration along the profile vary widely [Hamilton, 2008]. Tests for various features in the model, including the conductive feature in the mantle beneath the Bushveld Complex (which appears to be below this maximum penetration depth), as well as the conductive asthenospheric mantle south of the craton, are described in the text. The surface boundary of the craton is inferred from the position of surface faults [Cornell et al., 1986].

asthenosphere [Hamilton et al., 2006; Hamilton, 2008]. We have tested this possibility by running a series of inversions solving for a transversely anisotropic conductivity structure, solving for three distinct conductivities in directions parallel (Ryy) and perpendicular (Rxx) to the profile and in the vertical (Rzz). The inversion algorithm is regularized in the same way as the isotropic code [Evans et al., 2005; Baba et al., 2006]. There is an additional parameter, $\alpha$, which controls the degree of anisotropy permitted by the inversion. Setting $\alpha$ to 0 allows a freely anisotropic model, while increasing $\alpha$ forces the models in all three directions to be increasingly similar, resulting in an isotropic solution when $\alpha$ is large (typically $>100$ ). The inversion solves primarily for 2-D heterogeneity in resistivity structure and anisotropy is only included where needed to further decrease misfit. We have run inversions over a range of $\alpha$ in order to see the reduction achieved in misfit by introducing anisotropy. The value of $\alpha$ we chose to demonstrate possible levels of anisotropy is 0.1 (see Baba et al. [2006] for a comparison).

[18] It is well known that TM-mode data are more robust against the effects of 3-D structure [e.g., Jones, 1983b;
Wannamaker et al., 1984; Ledo et al. 2002]. Accordingly, we first ran a series of TM-only isotropic inversions. These models returned a surprisingly thin resistive lithosphere that is difficult to reconcile with any other data set from the Kaapvaal craton. However, the TM-mode data in the central portions of the profile, around Kimberley, are of quite poor quality with data from many stations having to be excluded from the inversion altogether, and so we have chosen to include the TE-mode phases and heavily down-weighted TE-mode apparent resistivities in our inversions. The inclusion of the additional mode degrades the total misfit, although the TE-mode phases can be fit better than the apparent resistivities. Vertical magnetic fields were only recorded by the LMT stations as the ground was too hard to allow burying the long BBMT coils in a vertical orientation. For this reason, the Tipper response is only available at $60 \mathrm{~km}$ spacing but has been included in the inversions where available. The preferred isotropic model resulting from inversions of selected data along the main profile is shown in Figure 3. The TM mode data and the response of the isotropic model are shown as pseudosections in Figure 4. We 


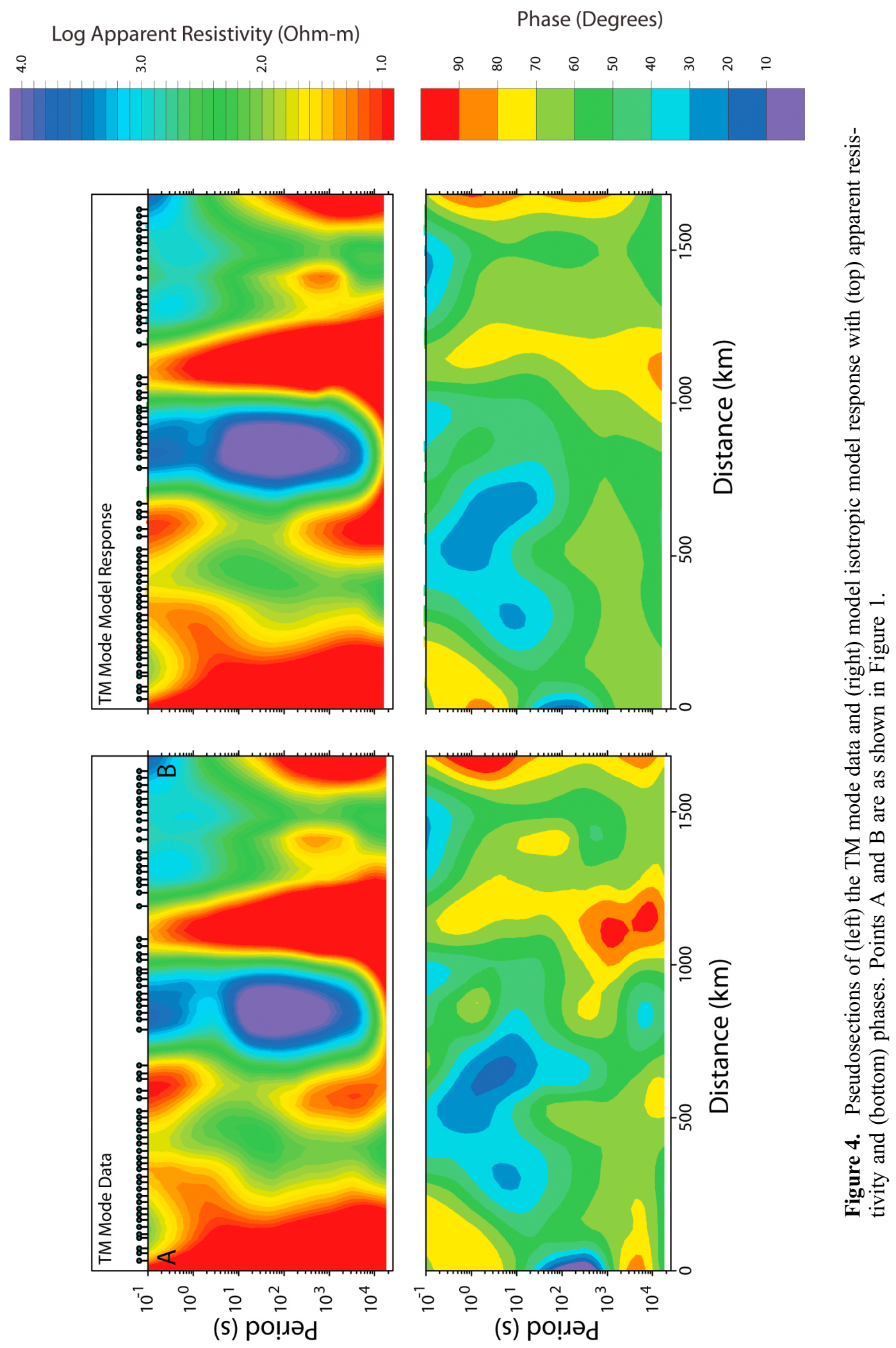


will discuss key features and how well they are resolved in sections 6.1-6.3.

\subsection{Resolution Tests}

[19] The resolution of MT data and the bounds on model parameters are notoriously hard to define. Linearized appraisals are possible [e.g., Schwalenberg et al., 2002], but, as the inverse problem in EM is so highly nonlinear, such approaches can fail to give accurate assessments, especially for resistive regions [e.g., Ledo and Jones, 2001]. Models derived from MT data are typically optimally smooth with the philosophy that minimum structure models should contain the minimum structure required to explain the data. The true Earth will certainly contain more structure than the model, but we can at least be confident that, at a minimum, the features in the model are required. The inversion algorithms we use offer a range of smoothing parameters and inversions need to be run over a wide range of these parameters before a preferred model is chosen on the basis of both misfit and model smoothness.

[20] Once key features are identified, placing bounds on their dimensions and properties is also a difficult undertaking. Unlike seismic tomography, for example, where discrete regions of a model can be largely analyzed for resolution in isolation from the rest of the model, the MT response at a given station can be influenced by many features in the model and a change to one region of the model can cause effects coupled with other features that might not be immediately or intuitively obvious. Approaches to addressing this problem include using the preferred model as a starting model, perturbing the feature of interest in some way (perhaps removing it entirely or altering its lower boundary) [e.g., Solon et al., 2005; Spratt et al., 2009] and seeing both the resultant change in misfit and, more importantly, whether the feature returns when the inversion is restarted. The inversion algorithm we have used offers several choices to help in this search:

[21] 1. It is possible to simply restart the inversion from the perturbed model and re-solve for the smoothest model possible. This test tries to ensure that the inversion result is not simply a local minimum in misfit space. If the feature of interest returns, then it is safe to assume that it is a required feature.

[22] 2. The inversion can be restarted to solve for the model closest to the perturbed model. This test makes sure that there are not any hidden trade-offs between different regions of the model. If there are, then the resultant model will have a similar misfit to the preferred model but with different features.

[23] 3. It is possible to "lock" the perturbed feature; this is a more stringent version of test 2 , in which the perturbation is forced to some degree to remain in the resultant model, although the degree to which the perturbation is locked is controlled by a weight function and can change if required by the data.

[24] Of course, field data are rarely ideal in quality, bandwidth and spatial density, and so a reasonable question might be whether the data would resolve a given feature even if they were as ideal as possible. This test can also verify which mode of data (TM or TE or both) has greatest sensitivity to certain features, such as the lithospheric thickness, for example. The preferred model can be used to generate a synthetic set of "ideal" data that can then be used in the same way as the real data to test the resolution of key features such as the lithosphere asthenosphere boundary. This is particularly true for the present case as the quality of the data around Kimberley and immediately to the northeast is poor owing to the effect of DC electric trains. We have generated synthetic data using a "generic" lithospheric model with a lithosphere-asthenosphere boundary at $200 \mathrm{~km}$ beneath the central Kaapvaal, and for which responses are calculated at the same station coverage as is used in the field data inversion. The test is whether these "ideal" data (with $5 \%$ noise and scatter added) are able to recover the original lithospheric thickness. In these synthetic tests we have run TM-only, TE-only and joint-mode inversions with starting models (1) a uniform half-space of $100 \Omega \mathrm{m}$ (2) a model close to the true model but with the lithosphere truncated at $100 \mathrm{~km}$ depth (3) a model with a truncated lithosphere as per (2) and with the resistivity cells locked beneath $100 \mathrm{~km}$. All tests returned a thick lithosphere, although the half-space starting model returned a transition at about $190 \mathrm{~km}$, slightly shallower than the initial reference model (note that vertical grid spacing at these depths in the model is around $10 \mathrm{~km}$ ). In all cases, the values of resistivity within the lithospheric mantle just above the LAB were lower than the starting values. Therefore, even for these ideal data, although the depth of the LAB defined on the transition to an adiabatic resistivity value of $100 \Omega \mathrm{m}$ is reasonably well resolved, there remain uncertainties in the structure of the lowermost lithosphere (i.e., does it have a dry or a wet composition). Despite this issue, we feel justified, with the usual caveats about 3-D impacts on TE mode data notwithstanding, in our choice of data for overall inversions.

\subsection{Lithosphere-Asthenosphere Transition Tests}

[25] On the basis of the definition given above (that the transition to asthenospheric mantle occurs at resistivities of $100 \Omega \mathrm{m}$ ) the maximum lithospheric thickness seen in inversions of our field data beneath the Kaapvaal craton is around $230 \mathrm{~km}$. There is ambiguity in our models over the resistivities in the lowermost part of the lithosphere, just above this transition. Isotropic inversions of the data return models with resistivities within the lower part of the lithosphere that are broadly consistent with thermal structure derived from heatflow measurements of a dry composition based on xenolith samples [Xu et al., 2000; Saltzer et al., 2001]. However, sensitivity tests suggest that a slightly more conductive (wet or anomalously hot) structure in a transition zone starting at around 150-180 km cannot be excluded. Anisotropic inversions of the data show differences in the conductivities parallel and perpendicular to profile, with the most conductive direction parallel to the profile.

[26] We have tested resolution within the lowermost lithosphere in a number of ways. These involve taking the preferred model of resistivity structure and perturbing it as described above. Specific tests carried out include: setting the resistivity at $130 \mathrm{~km}$ and deeper to be $100 \Omega \mathrm{m}$ and (1) re-solve for the smoothest model from this starting point; (2) solve for the smoothest model closest to this starting model (i.e., use the starting model as an a priori constraint in the inversion); (3) "lock" the resistivities from $130 \mathrm{~km}$ to $\sim 200 \mathrm{~km}$ at $100 \Omega \mathrm{m}$; and (4) "lock" the resistivities from 100 to $\sim 200 \mathrm{~km}$ at $100 \Omega \mathrm{m}$. When locking the resistivities, 


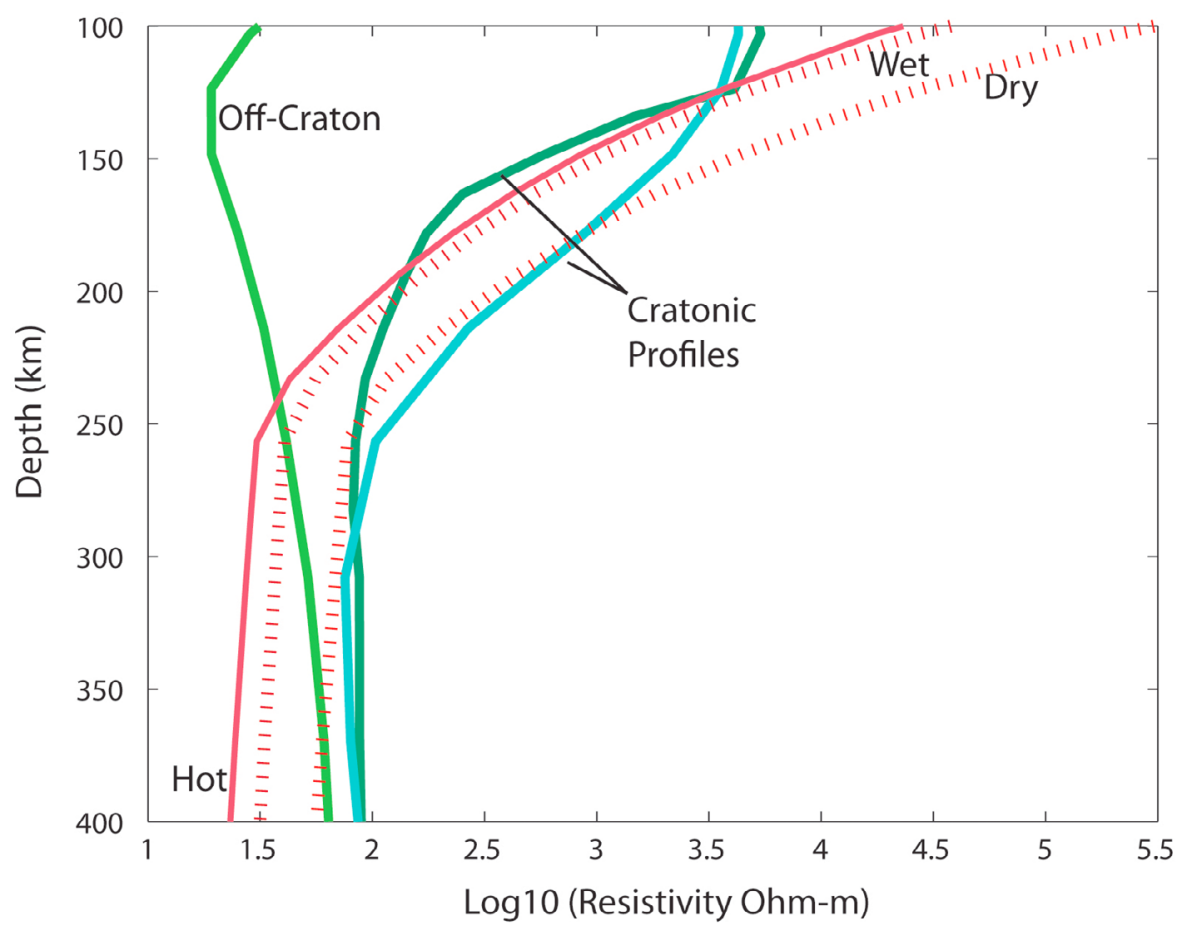

Figure 5. Profiles of lithospheric resistivity through models run to test sensitivity to the top of the asthenosphere depth as discussed in the text. The cratonic profiles are averaged laterally through the inversion models over an interval of uniform lithospheric thickness. In general, the depth to asthenosphere, defined as the depth at which resistivities hit an adiabatic value of $100 \Omega \mathrm{m}$, is around $230 \mathrm{~km}$ for our models. The blue line is a cross section through the inversion model in Figure 3, while the dark green cratonic profile is representative of the inversion tests described in the text in which the lower lithosphere is perturbed and the inversion restarted. The dashed line (dry) is the predicted resistivity profile based on the geotherm of Jones [1988] and assuming a dry cratonic and asthenospheric composition, as well as a mean composition given by Saltzer et al. [2001]. All models are more conductive than this geotherm would predict within the cratonic lithospheric mantle, particularly at depths shallower than $150 \mathrm{~km}$. Deeper than $\sim 150 \mathrm{~km}$, our models have ambiguity in structure, with no obvious preference in isotropic inversions between a warm/damp lowermost lithosphere and a dry structure. The dashed line (wet) shows the effect of adding $3000 \mathrm{H} / 10^{6} \mathrm{Si}$ and assuming a Nernst-Einstein conductivity model based on the diffusivity of hydrogen [Hirth et al., 2000]. The red line (hot) shows the effect of adding $150^{\circ} \mathrm{C}$ to the geotherm.

the values in these locked cells are weighted such that the algorithm prefers to keep them at their starting values, but deviations from these values are allowed if required.

[27] In all cases, the top of the asthenosphere returns to depths of around $230 \mathrm{~km}$ with similar misfits to the original inversion result. However, in all cases, the resistivities of the lithosphere from the asthenosphere to depths of around $\sim 150 \mathrm{~km}$ are in the range of 100-300 $\Omega \mathrm{m}$, substantially lower than might be expected for a cratonic geotherm (Figure 5). It should be noted that these inversions are inherently smooth; they are chosen to find minimum structure models such that sharp boundaries are often smoothed as a result. Other reports on electrical lithosphere have often employed some combination of data followed by a 1-D inversion which allows sharp jumps in conductivity. In these cases, the lithospheric thicknesses reported are somewhat thicker. However, the tests we have run have inserted this kind of sharp boundary into our models and we have allowed the model to keep such a feature, yet in all cases the inversion prefers a smoother lithosphere-asthenosphere transition.

\subsection{Anisotropic Inversion}

[28] Electrical resistivity in the Kaapvaal mantle (both lithospheric and asthenospheric) has been shown to have a higher value in a direction parallel to the strike of our profile [Hamilton et al., 2006], although this analysis is based on tensor decomposition and has some ambiguity in terms of causality: the response could be either due to large-scale 2or 3-D structure or to anisotropy. Noting that electrical conductivities in the asthenosphere surrounding the Kaapvaal are higher than expected for a dry composition, we ran a series of inversions solving for anisotropic resistivity structure [Evans et al., 2005; Baba et al., 2006]. Models with extreme levels of anisotropy show smooth electrical structure but with higher values in the direction parallel to the survey profile, which in turn is roughly parallel to inferred modernday flow in the mantle [Behn et al., 2004] (Figure 6). Fur- 


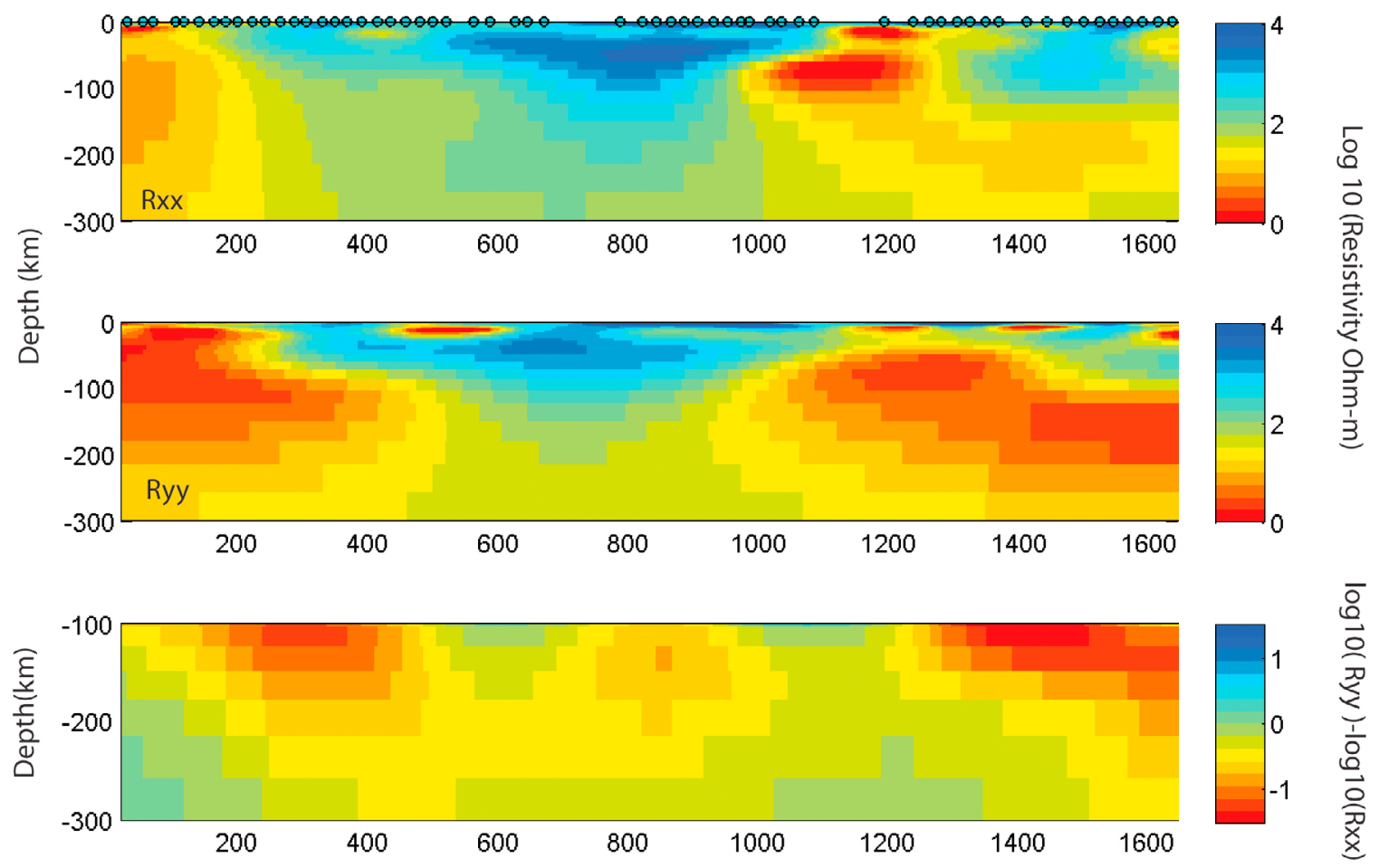

Figure 6. (top and middle) Anisotropic models for the Kaapvaal data. Conductivity in the direction perpendicular to the profile (Rxx) and parallel to the profile (Ryy) are shown. (bottom) The levels of anisotropy calculated as the difference in Log10(resistivity) between the Ryy and Rxx models.

thermore, the model of conductivity perpendicular to the profile shows the highest resistivities at the base of the Kaapvaal lithosphere, with values parallel to the profile (and hence mantle flow direction) having slightly lower values (by about 1/2-3/4 an order of magnitude). The model shown in Figure 6 is somewhat conservative as it is slightly smoother than the preferred isotropic model. The reduction in misfit achieved (in the anisotropic code) by introducing anisotropy is quite modest and is below the level of statistical significance and so anisotropy is not a required feature of our data.

\section{Discussion}

7.1. Electrical Structure of the Lowermost Lithosphere and Asthenosphere: Water, Melt, and Electrical Anisotropy

[29] A seismic tomography model [Fouch et al., 2004] shows a single high-velocity root beneath the Kaapvaal craton, although there is a hint of two separate regions of higher velocity on either side of Kimberley. Our model shows a more fragmented electrical lithosphere with a break in the most resistive portions of the lithosphere on either side of the Kimberley region. However, the data quality around Kimberley is poor owing to noise contamination of electric field signal from electric trains and mining activity, and so this feature of our model is not well constrained. Consistent with the idea that diamondiferous kimberlites are found in regions of gradients in the lithospheric thickness, the lithospheric thickness around Kimberley based on a model, ignoring the apparent conductivity break (i.e., the most conservative (deepest) estimate of depth to the asthenosphere), is 160$180 \mathrm{~km}$, somewhat thinner than the maximum to the north and thinning substantially to the south.

[30] Higher conductivities within the lower reaches of the lithosphere, if real, could be related to the suggested low shear velocities described by $L i$ and Burke [2006]. The shear velocity anomalies are suggested to be caused by a thermal transition layer in which mantle convection is able to occur. Another possibility is that this region is similar to the transition zone discussed by Lee et al. [2005], and marks a transition from a dry-rigid lithosphere into a wetter and less rigid boundary layer that may break off and be carried down into the convecting mantle. Excess temperatures of around $150^{\circ} \mathrm{C}$ would be needed to explain the conductivities in our models at depths of around $150 \mathrm{~km}$. Water contents are harder to estimate given the large variations in current laboratory results.

[31] The anisotropic models (Figure 6) suggest higher conductivities within the lowermost lithospheric mantle in a direction parallel to our profile, which would not be compatible with a simple thermal anomaly, although as stated above there is no statistical reason to prefer this model over the isotropic solution. However, given the ambiguity in the resistivity of the lowermost lithosphere and the high conductivities in the surrounding asthenosphere, it is worth discussing possible causes of anisotropy within the mantle, as they are controversial and also relate to the discussion of enhanced conductivity in general. 
[32] Dissolved hydrogen in olivine has been suggested as a potential mechanism that could cause electrical anisotropy [Karato, 1990, 2006], but laboratory data to support this assertion are conflicting [Wang et al., 2006; Yoshino et al., 2006, 2009; Poe et al., 2010], with vigorous discussion between the competing groups [e.g., Karato and Dai, 2009; Yoshino and Katsura, 2009]. There seems little doubt that hydrous olivine is more electrically conductive than is dry olivine, although there are differences in the measured activation energies between the different data sets measured resulting in different magnitudes of enhancement. The selfdiffusivity of hydrogen in olivine has been seen to be significantly faster along the $a$ axis of olivine at temperatures up to about $1100^{\circ} \mathrm{C}$ [Kohlstedt and Mackwell, 1998]. However, higher temperature measurements of chemical diffusivity reveal different mechanisms with the $a$ axis (the axis expected to be preferentially aligned owing to mantle flow) no longer the fastest diffusion direction [Demouchy and Mackwell, 2006]. Laboratory measurements of the conductivity of hydrous olivine are complicated by the difficulty of holding water within the sample at high temperatures. As a result, well characterized measurements of conductivity made on single crystals of olivine as a function of water content are limited to temperatures less than about $800^{\circ} \mathrm{C}$ [Poe et al., 2010], with conductivities at high temperatures extrapolated from these data. These single grain measurements do not, by definition, include any effects of grain boundary conduction mechanisms. Poe et al. [2010] suggest that at low temperature the conductivity is controlled by a proton-bearing charge carrier, with a different small polaron conduction mechanism taking over at a temperature that is dependent on the water concentration. This interpretation is more or less consistent with the recent diffusivity measurements [Demouchy and Mackwell, 2006]. The possibility of different transport mechanisms operating at these higher temperatures could make the extrapolation of conductivity problematic but, in any event, the $a$ axis is not predicted to be the most conductive except at very high water contents ( 2000 ppm) [Poe et al., 2010], much higher than is reported for the Kaapvaal lithospheric mantle $(<\sim 70 \mathrm{ppm})$ [Peslier et al., 2010]. The approach adopted for high-temperature measurements on olivine aggregates is to make measurements quickly and to measure water contents before and after measurement [Wang et al., 2006]. Samples without substantial water loss are used to calculate activation energies. However, since the activation energies are dependent on water contents, uncertainties in water content at each data point could greatly influence the interpretation. Finally, because the extant high-temperature measurements have been made on aggregates, they do not shed any light on conductivity anisotropy.

[33] Using Nernst-Einstein type relationships (assuming hydrogen self-diffusivity controls conductivity) to determine the impact of dissolved hydrogen on olivine conductivity [Karato, 1990; Hirth et al., 2000; Evans et al., 2005; Wang et al., 2006] suggests that for an isotropic mantle fabric $\sim 3000 \mathrm{H} / 10^{6} \mathrm{Si}$ (or $\sim 200 \mathrm{wt}$ ppm water) would be needed to explain the conductivities in the lower lithosphere. Such levels are four or more times higher than are reported for the Kaapvaal [e.g., Peslier et al., 2010]. There have been suggestions that Light Rare Earth Element enrichments seen in some xenolith samples are suggestive of refertilization of some portions of the mantle that might result in higher water contents than might be expected for an Archean mantle that has undergone extensive melting (and hence removal of water). Evidence for such late-stage metasomatic events exists in garnet inclusions in diamonds [Banas et al., 2009], and also in xenoliths of different ages [Griffin et al., 2003; Kobussen et al., 2008]. The xenolith data show thinning of the depleted mantle somewhere between 108 and $117 \mathrm{Ma}$. In any case, given the large uncertainties in electrical structure in this part of the mantle owing to limitations of the data and the large variations in laboratory measurements on water enhanced conductivity in olivine, the value of $200 \mathrm{ppm}$ should be regarded as somewhat of an upper bound on the allowable water contents.

[34] Recent data suggest that water can also influence the conductivities of both opx and garnet [Dai and Karato, 2009a, $2009 \mathrm{~b}]$. The enhancement in conductivity is pronounced for both minerals, as for olivine [Poe et al., 2010], at low temperatures (less than about $800^{\circ} \mathrm{C}$ ), where conductivities are several orders of magnitude greater than for equivalent dry mineral compositions. Mierdel et al. [2007] show that aluminous opx can hold large quantities of water under lithospheric mantle conditions. Given that conductivities of hydrous olivine, opx and garnet have all been measured to be significantly enhanced at lithospheric temperatures with fairly small water contents, the this can explain the lower than expected lithospheric resistivities for dry compositions on the Kaapvaal geotherm [Jones, 1988] at depths shallower than $\sim 150 \mathrm{~km}$ (Figure 3).

[35] Mantle conductivities at depths deeper than about $100 \mathrm{~km}$ to the south of the craton appear to be high in our models. Penetration depth of data in this region is somewhat limited by shielding owing to shallow crustal features. However, running tests on this conductive region shows that the inversion consistently requires an enhanced conductivity with misfit significantly degraded if the conductivity is set to lower values.

[36] Melt is another potential mechanism that can enhance conductivity, but although melt is a possibility in the asthenosphere it is unlikely in the lowermost parts of the Kaapvaal lithospheric mantle. Models of anisotropic melt networks from laboratory studies generally do not show uniaxial alignment that would correspondingly result in significant electrical anisotropy [Holtzman et al., 2003], although new laboratory data have been measured that do show anisotropic melt networks in samples that have been sheared (G. Manthilake, personal communication, 2010; see also Caricchi et al. [2011]). If asthenospheric melts are carbonatites then only trace amounts are needed to substantially raise electrical conductivity to the levels seen [Gaillard et al., 2008], to the extent that electrical measurements might be the only means of detection.

\subsection{Bushveld Complex}

[37] The Kaapvaal craton has been impacted by four major magmatic events of which the most significant resulted in the Bushveld Complex, dated at 2.05 Ga. The Bushveld Complex is the largest layered igneous intrusion on Earth with an estimated volume of $0.5-1.0 \times 10^{6} \mathrm{~km}^{3}$ [Von Gruenewaldt et al., 1985]. Several models exist for the genesis of large flood-basalt magmatic intrusions and these include: a plume source [e.g., Hatton, 1995; Zhang et al., 2008]; melting due 
to adiabatic decompression resulting from either rifting and lithospheric thinning [e.g., White and McKenzie, 1995] or delamination [e.g., Conrad and Molnar, 1997]; and the upward draining of a pool of melt at the base of the lithosphere [Silver et al., 2006].

[38] Seismic velocities from tomography beneath the Bushveld Complex are significantly lower than beneath the neighboring craton. These low velocities are interpreted to be due either to enrichment of basaltic components (e.g., Fe, $\mathrm{Cpx}$ ), as a result refertilization during the magmatic event, or might be due to metasomatizing fluids that hydrated the mantle [James et al., 2001; Shirey et al., 2002]. Electrical conductivity within the Bushveld Complex is extremely high. There are two conductive regions, one in the crust beneath the surface expression of the western Bushveld, and the other in the mantle at a depth of around $60 \mathrm{~km}$, centered about $100 \mathrm{~km}$ to the south. The crustal conductors are likely related to metal and heavy metal (platinum group elements) mineralization, as the Bushveld is known to contain economic deposits [e.g., Arndt et al., 2005]. The mantle conductor is more cryptic and, since the possibility arises that the crustal feature might contaminate the ability of the data to constrain the deeper mantle structure, with apparently limited penetration of signal based on a 1-D estimate, we verified through tests similar to those discussed above, that the mantle feature is required by the data.

[39] In a similar manner as for the LAB tests we have started with a preferred model and perturbed it by removing the mantle conductor. We then ran a series of inversions to see whether the conductor returned under the same constraining conditions as before. For the initial model the mantle conductor was removed and the resistivity set to $100 \Omega \mathrm{m}$. This value is considerably lower than expected for lithospheric mantle but is consistent with surrounding mantle values beneath the rest of the Bushveld. Inversions were run: (1) Solving for the smoothest model; (2) solving for model closest to this new starting model; and (3) solving with resistivities "locked" in the altered region. In all cases, the conductor returns in the same location with the top of the conductor around $60 \mathrm{~km}$ depth and a conductance of approximately $15,000 \mathrm{~S}$.

[40] At the mantle depths where the strong conductor appears in the model $(\sim 60-85 \mathrm{~km})$, the temperatures based on heatflow data are predicted to be in the region of 500 $600^{\circ} \mathrm{C}$ [Jones, 1988]. Of course, these heatflow data are typical for the entire craton and we know that the Bushveld had a thermal event, but the latest of these events was in the Archean. Assuming that these temperatures are appropriate for the Bushveld, we can rule out melt as an explanation for the conductor as the region is well below the solidus.

[41] There are two scenarios for the emplacement of conductive mechanisms in the mantle beneath the Bushveld: either the mantle was already conductive prior to the Bushveld magmatic event, which is possible if the Bushveld magmatism exploited existing lithospheric weaknesses, or the magmatism itself introduced a conductive phase. There is also the possibility that the magmatism reacted with a prior structure to form a connected conductive feature. A prior structure suggests that the magmatism took advantage of a preexisting weakness in order to penetrate the crust, and there is some evidence for this from SKS splitting analyses [Silver et al., 2006]. A weak zone could be a suture associated with the Limpopo belt which joins the Kaapvaal to the Zimbabwe craton. Within the suture zone could be a section of oceanic arc mantle. Here, we might expect fairly abundant carbon in the form of graphite to be present and this would be one potential conduction mechanism in much the same way as has been suggested in the Slave craton [Jones et al., 2001, 2003]. In the Slave craton, seismic receiver functions show a seismic reflector coincident with the high conductivity zone [Moorkamp et al., 2007, 2010; Chen et al., 2009]. No similar anomalous region exists for the Kaapvaal craton. Another explanation, related to the existence of an oceanic section, is subduction-related eclogite within the mantle. Xenoliths from Premier kimberlite pipe (erupted at $\sim 1.2 \mathrm{Ga}$ and significantly postdating the Bushveld magmatism) are primarily garnet eclogites with diamonds from the region also showing primarily eclogitic paragenesis [Shirey et al., 2004], although the diamonds originate from much deeper than the conductive anomaly. Iron-rich (almandine) garnet has a significantly higher conductivity [Romano et al., 2006] than other mantle minerals, even at the temperatures expected for this old section of lithospheric mantle. Although the high garnet content predicts a higher conductivity for these samples compared to an olivine-rich mantle, the garnet content in these xenoliths is not high enough to explain the very high conductivity beneath the Bushveld. However, high-pressure subduction zone eclogites commonly consist of high-volume fractions (around 50\%) of Fe-rich garnet (H. Marschall, personal communication, 2009; see also Konrad-Schmolke et al. [2008]), so it is possible that the xenolith suite is biased toward lower garnet contents. Further, iron-rich garnets can be highly conductive (around $1 \mathrm{~S} / \mathrm{m}$ ) at low temperatures [Romano et al., 2006]. The bulk conductivity of an eclogite will depend on the concentration of almandine and the grain contacts between them: if the garnets sit as isolated inclusions, or there is no means of connecting them electrically, then they will not greatly enhance bulk conductivity. Deformation during craton assembly might be one means of shearing the grains and establishing connectivity. However, there is almost no extant laboratory data on the bulk conductivity of eclogites, and what does exist does not show high conductivities [Lastovickova and Buben, 1975].

[42] If the source of the high conductivity is associated with the magmatic intrusion itself, then a possible explanation could be metallic sulphides distributed in a connected network through the pluton [e.g., Ducea and Park, 2000]. It is well known that sulphide minerals are abundant within the crustal reaches of the Bushveld Complex [e.g., Arndt et al., 2005], although they are concentrated by channelized flow to economically viable levels. Jones and Garcia [2006] appealed to sulphidic mineralization within the mantle lithosphere to explain the reduced resistivities observed directly below the Yellowknife Fault in the southern part of the Slave craton, northern Canada. The distribution of sulphides within the mantle, with sulphide minerals frozen in place as melt crystallizes, is less well known. Perhaps the sulphides act to connect garnets within eclogite forming a connected network of conductors through this region of the mantle. Such a model would place less stringent require- 
ments on the connectivity of the sulphide melt network and might be a more feasible network to achieve.

\section{Conclusions}

[43] A large MT survey across southern Africa has shown large variations in mantle electrical structure related to lateral changes in lithospheric structure. The Kaapvaal craton has a resistive root with an onset of asthenosphere at around $230 \mathrm{~km}$. The transition between obviously dry and rigid lithosphere and asthenosphere is not well resolved by our data.

[44] The lithospheric structure around Kimberley is also poorly resolved, owing to the effects of train and mining noise in our data. However, the lithosphere is thinner around Kimberley than in the central portions of the craton, just to the north. The mantle beneath the Bushveld is highly disrupted in its electrical structure, with regions of high electrical conductivity, some of which are associated with economic mineral deposits. Both Kimberley and the Bushveld areas are regions of economic diamond production. The uppermost $\sim 150 \mathrm{~km}$ or so of lithosphere is more conductive than expected for a dry composition on the reported Kaapvaal geotherm. The small amounts of water reported for xenoliths from the Kaapvaal [Peslier et al., 2010], along with reported enhancements in conductivity for olivine for quite modest amounts of water at temperatures below $\sim 800^{\circ} \mathrm{C}$ [Poe et al., 2010; Yoshino et al., 2009; Wang et al., 2006; Dai and Karato, 2009c] as well as opx [Dai and Karato, 2009a] could explain these enhanced conductivities. The asthenosphere surrounding the Kaapvaal is surprisingly conductive, suggesting the presence of abundant water or trace amounts of melt, or both.

[45] Acknowledgments. Three institutions and one company came together to initiate SAMTEX in 2002: the Dublin Institute for Advanced Studies (academia),Woods Hole Oceanographic Institution (academia), the Council for Geoscience (government), and De Beers Group Services (industry). Seven others joined SAMTEX during the four phases of acquisition. In chronological order: the University of the Witwatersrand (academia), Geological Survey of Namibia (government), Geological Survey of Botswana (government), Rio Tinto Mining and Exploration (industry), BHP Billiton (industry), Council for Scientific and Industrial Research of South Africa (government), and ABB Sweden (industry) for the Namibian Power Corporation (government). Other members of the SAMTEX team include: L. Collins, C. Hogg, C. Horan, G. Wallace, M. Miensopust (DIAS), A. D. Chave (WHOI), J. Cole, P. Cole, R. Stettler (CGS), T. Ngwisanyi, G. Tshoso (GSB), D. Hutchins, T. Katjiuongua (GSN), E. Cunion, A. Mountford, T. Aravanis (RTME), W. Pettit, D. Khoza (BHPB), H. Jelsma (De Beers), P.-E. Share (CSIR), and J. Wasborg (ABB). We gratefully acknowledge the tremendous contribution made to this work by a large number of people involved in several phases of data acquisition across southern Africa. Many, but not all, are employed by SAMTEX consortium members. We also thank Phoenix Geophysics, the Geological Survey of Canada, and the U.S. EMSOC for providing instrumentation. In addition to the funding and logistical support provided by SAMTEX consortium members, this work is also supported by research grants from the National Science Foundation (EAR-0309584 and EAR-0455242 through the Continental Dynamics Program), the Department of Science and Technology, South Africa, and Science Foundation of Ireland (grant 05/RFP/ GEO001). We are very much indebted to countless farmers and landowners across the subcontinent for allowing us to site MT stations on their properties and for their assistance and hospitality as sites were installed. Two anonymous reviewers are thanked for comments on a previous draft of the manuscript.

\section{References}

Anderson, D. L. (1995), Lithosphere, asthenosphere, and perisphere, Rev. Geophys., 33, 125-149, doi:10.1029/94RG02785.

Arndt, N. T., C. M. Lesher, and G. K. Czamanske (2005) Mantle-derived magmas and magmatic Ni-Cu-(PGE) deposits, in Economic Geology: 100th Anniversary Volume, pp. 5-23, Soc. of Econ. Geol., Littleton, Colo.

Artemieva, I. M. (2009a) Mantle xenoliths may be non-representative of the cratonic mantle: Geophysical perspective, paper presented at the 2009 Annual Meeting, Geol. Soc. of Am., Portland, Oreg., 18-21 Oct.

Artemieva, I. M. (2009b), The continental lithosphere: Reconciling thermal, seismic, and petrologic data, Lithos, 109, 23-46, doi:10.1016/j. lithos.2008.09.015.

Baba, K., A. D. Chave, R. L. Evans, G. Hirth, and R. L. Mackie (2006), Mantle dynamics beneath the East Pacific Rise at $17^{\circ} \mathrm{S}$ : Insights from the Mantle Electromagnetic and Tomography (MELT) experiment, J. Geophys. Res., 111, B02101, doi:10.1029/2004JB003598.

Banas, A., T. Stachel, D. Phillips, N. Shimizu, K. S. Viljoen, and J. W. Harris (2009), Ancient metasomatism recorded by ultra-depleted garnet inclusions in diamonds from DeBeers Pool, South Africa, Lithos, 112, 736-746, doi:10.1016/j.lithos.2009.04.043.

Behn, M. D., C. P. Conrad, and P. Silver (2004), Detection of upper mantle flow associated with the African Superplume, Earth Planet. Sci. Lett., 224, 259-274, doi:10.1016/j.eps1.2004.05.026.

Ben-Ismail, W., G. Barruol, and D. Mainprice (2001), The Kaapvaal craton seismic anisotropy: Petrophysical analyses of upper mantle kimberlite nodules, Geophys. Res. Lett., 28, 2497-2500, doi:10.1029/2000GL012419.

Boyd, F. R., and J. J. Gurney (1986), Diamonds and the African lithosphere, Science, 232, 472-477, doi:10.1126/science.232.4749.472.

Boyd, F. R., and P. H. Nixon (1978), Ultramafic nodules from the Kimberley pipes, South Africa, Geochim. Cosmochim. Acta, 42, 1367-1382, doi:10.1016/0016-7037(78)90042-X.

Boyd, F. R., J. J. Gurney, and S. H. Richardson (1985), Evidence for a 150-200 km thick Archean lithosphere from diamond inclusion thermobarometry, Nature, 315, 387-389, doi:10.1038/315387a0.

Caricchi, L., F. Gaillard, J. Mecklenburgh, and E. Le Trong (2011), Experimental determination of electrical conductivity during deformation of melt-bearing olivine aggregates and electrical anisotropy in the oceanic low velocity zone, Earth Planet. Sci. Lett., 302, 81-94, doi:10.1016/j. epsl.2010.11.041.

Chave, A. D., and D. J. Thomson (2004), Bounded influence magnetotelluric response function estimation, Geophys. J. Int., 157, 988-1006, doi:10.1111/j.1365-246X.2004.02203.x.

Chen, C.-W., S. Rondenay, R. L. Evans, and D. Snyder (2009), Geophysical detection of relict metasomatism from an Archaean subduction zone, Science, 326, 1089-1091, doi:10.1126/science.1178477.

Conrad, C. P., and P. Molnar (1997), The growth of Rayleigh-Taylor-type instabilities in the lithosphere for various rheological and density structures, Geophys. J. Int., 129, 95-112, doi:10.1111/j.1365-246X.1997. tb00939.x.

Cornell, D. H., C. J. Hawkesworth, P. Van Calsteren, and W. D. Scott (1986), Sm-Nd study of Precambrian crustal development in the Prieska-Copperton region, Cape Province, Trans. Geol. Soc. S. Afr., 89, $17-28$.

Dai, L., and S.-I. Karato (2009a), Electrical conductivity of orthopyroxene: Implications for the water content of the asthenosphere, Proc. Jpn. Acad., Ser. B, 85, 466-475.

Dai, L., and S.-I. Karato (2009b), Electrical conductivity of pyrope-rich garnet at high temperature and high pressure, Phys. Earth. Planet. Int., 176, $83-88$.

Dai, L., and S.-I. Karato (2009c), Electrical conductivity of wadsleyite under high pressures and temperatures, Earth Planet. Sci. Lett., 287, 277-283.

Demouchy, S., and S. Mackwell (2006), Mechanisms of hydrogen incorporation and diffusion in iron-bearing olivine, Phys. Chem. Miner., 33, 347-355, doi:10.1007/s00269-006-0081-2.

de Wit, M. J., and J. H. Tinker (2004), Crustal structure across the central Kaapvaal craton from deep-seismic reflection data, S. Afr. J. Geol., 107, 185-206, doi:10.2113/107.1-2.185.

de Wit, M. J., C. Roering, R. J. Hart, R. A. Armstrong, C. E. J. de Ronde, R. W. E. Green, M. Tredoux, E. Peberdy, and R. A. Hart (1992), Formation of an Archean continent, Nature, 357, 553-562, doi:10.1038/ $357553 \mathrm{a} 0$

Ducea, M. N., and S. K. Park (2000), Enhanced conductivity from sulfide minerals, southern Sierra Nevada, California, Geophys. Res. Lett., 27, 2405-2408, doi:10.1029/2000GL011565.

Eaton, D. W., F. Darbyshire, R. L. Evans, H. Grütter, A. G. Jones, and X. Yuan (2009), The elusive lithosphere-asthenosphere boundary (LAB) beneath cratons, Lithos, 109, 1-22, doi:10.1016/j.lithos.2008.05.009. 
Egbert, G. D. (1997), Robust multiple-station magnetotelluric data processing, Geophys. J. Int., 130, 475-496, doi:10.1111/j.1365-246X.1997. tb05663.x.

Evans, R. L., G. Hirth, K. Baba, D. Forsyth, A. Chave, and R. Mackie (2005), Geophysical controls from the MELT area for compositional controls on oceanic plates, Nature, 437, 249-252, doi:10.1038/nature04014

Fouch, M. J., D. E. James, J. VanDecar, and S. van der Lee, and the Kaapvaa Seismic Group (2004), Mantle seismic structure beneath the Kaapvaal and Zimbabwe cratons, S. Afr. J. Geol., 107, 33-44, doi:10.2113/107.1-2.33.

Gaillard, F., M. Malki, G. Iacono-Maziano, M. Pichavant, and B. Scaillet (2008), Carbonatite melts and electrical conductivity in the asthenosphere, Science, 322, 1363-1365, doi:10.1126/science.1164446.

Griffin, W. L., S. Y. O'Reilly, L. M. Natapov, and C. G. Ryan (2003), The evolution of lithospheric mantle beneath the Kalahari craton and its margins, Lithos, 71, 215-241, doi:10.1016/j.lithos.2003.07.006.

Grütter, H., D. Latti, and A. Menzies (2006), Cr-saturation arrays in concentrate garnet compositions from kimberlite and their use in mantle barometry, J. Petrol., 47, 801-820, doi:10.1093/petrology/egi096.

Hamilton, M. P. (2008) Electrical and seismic anisotropy of the lithosphere with the focus on central southern Africa, Ph.D. thesis, Univ. of the Witwatersrand, Johannesburg, South Africa.

Hamilton, M. P., A. G. Jones, R. L. Evans, S. Evans, C. J. S. Fourie, X. Garcia, A. Mountford, J. Spratt, and the SAMTEX Team (2006), Electrical anisotropy of South African lithosphere compared with seismic anisotropy from shear-wave splitting analyses, Phys. Earth Planet. Inter. 158, 226-239, doi:10.1016/j.pepi.2006.03.027

Hansen, S. E., A. Nyblade, J. Julia, P. H. G. M. Dirks, and R. Durrheim (2009), Upper-mantle low-velocity zone structure beneath the Kaapvaal craton from S-wave receiver functions, Geophys. J. Int., 178 , 1021-1027, doi:10.1111/j.1365-246X.2009.04178.x.

Hatton, C. J. (1995), Mantle plume origin for the Bushveld and Ventersdorp magmatic provinces, J. Afr. Earth Sci., 21, 571-577, doi:10.1016 0899-5362(95)00106-9.

Hirth, G., and D. L. Kohlstedt (1996), Water in the oceanic upper mantle: Implications for rheology, melt extraction and the evolution of the lithosphere, Earth Planet. Sci. Lett., 144, 93-108, doi:10.1016/0012-821X (96)00154-9.

Hirth, G., R. L. Evans, and A. D. Chave (2000), Comparison of continental and oceanic mantle electrical conductivity: Is the Archean lithosphere dry? Geochem. Geophys. Geosyst., 1(12), 1030, doi:10.1029/2000GC000048.

Holtzman, B. K., D. L. Kohlstedt, M. E. Zimmerman, F. Heidelbach, T. Hiraga, and J. Hustoft (2003), Melt segregation and strain partitioning Implications for seismic anisotropy and mantle flow, Science, 301, 1227-1230, doi:10.1126/science. 1087132 .

James, D. E., M. J. Fouch, J. C. VanDecar, and S. van der Lee, and the Kaapvaal Seismic Group (2001), Tectospheric structure beneath southern Africa, Geophys. Res. Lett., 28, 2485-2488, doi:10.1029/2000GL012578.

James, D. E., F. R. Boyd, D. Schutt, D. R. Bell, and R. W. Carlson (2004) Xenolith constraints on seismic velocities in the upper mantle beneath southern Africa, Geochem. Geophys. Geosyst., 5, Q01002, doi:10.1029/ 2003GC000551.

Jones, A. G. (1983a), On the equivalence of the Niblett and Bostick transformations in the magnetotelluric method, J. Geophys., 53, 72-73.

Jones, A. G. (1983b), The problem of "current channeling": A critical review, Geophys. Surv., 6, 79-122, doi:10.1007/BF01453996.

Jones, A. G. (1983c), On the equivalence of the "Niblett" and "Bostick" transformations in the magnetotelluric method, J. Geophys., 53, 72-73.

Jones, A. G. (1999), Imaging the continental upper mantle using electromagnetic methods, Lithos, 48, 57-80, doi:10.1016/S0024-4937(99) $00022-5$

Jones, A. G., and X. Garcia (2006), Electrical resistivity structure of the Yellowknife River Fault Zone and surrounding region, in Gold in the Yellowknife Greenstone Belt, Northwest Territories: Results of the EXTECH III Multidisciplinary Research Project, Spec. Publ. 3, chap. 10 pp. 126-141, Miner. Deposits Div., Geol. Assoc. of Can., St. John's, Newfoundland.

Jones, A. G., and H. Joedicke (1984) Magnetotelluric transfer function estimation improvement by a coherence-based rejection technique, paper presented at the 54th Annual Meeting, Soc. Explor. Geophys., Atlanta, Ga., 2-6 Dec.

Jones, A. G., A. D. Chave, D. Auld, K. Bahr, and G. Egbert (1989), A comparison of techniques for magnetotelluric response function estimation, J. Geophys. Res., 94, 14,201-14,213, doi:10.1029/JB094iB10p14201.

Jones, A. G., I. J. Ferguson, A. D. Chave, R. L. Evans, and G. W. McNeice (2001), The electric lithosphere of the Slave craton, Geology, 29 , 423-426, doi:10.1130/0091-7613(2001)029<0423:ELOTSC $>2.0$. CO;2.

Jones, A. G., P. Lezaeta, I. J. Ferguson, A. D. Chave, R. Evans, X. Garcia and J. Spratt (2003), The electrical structure of the Slave craton, Lithos, 71, 505-527, doi:10.1016/j.lithos.2003.08.001
Jones, A. G., R. L. Evans, and D. W. Eaton (2009a), Velocity-conductivity relationships for mantle mineral assemblages in Archean cratonic lithosphere based on a review of laboratory data and application of extrema bound theory, Lithos, 109, 131-143, doi:10.1016/j.lithos.2008.10.014.

Jones, A. G., et al. (2009b), Area selection for diamonds using magnetotellurics: Examples from southern Africa, Lithos, 112, suppl. 1, 83-92, doi:10.1016/j.lithos.2009.06.011.

Jones, M. Q. W. (1988), Heat flow in the Witwatersrand Basin and environs and its significance for the South African shield geotherm and lithospheric thickness, J. Geophys. Res., 93, 3243-3260, doi:10.1029/ JB093iB04p03243.

Karato, S. (1990), The role of hydrogen in the electrical conductivity of the upper mantle, Nature, 347, 272-273, doi:10.1038/347272a0.

Karato, S. (2006), Remote sensing of hydrogen in Earth's mantle, in Water in Nominally Anhydrous Minerals, edited by H. Keppler and J. Smyth, pp. 343-375, Mineral. Soc. of Am., Washington, D. C.

Karato, S., and L. Dai (2009), Comments on "Electrical conductivity of wadsleyite as a function of temperature and water content" by Manthilake et al., Phys. Earth Planet. Inter., 174, 19-21, doi:10.1016/j.pepi. 2009.01.011.

Kobussen, A. F., W. L. Griffin, S. O'Reilly, and S. R. Shee (2008), Ghosts of lithosphere past: Imaging an evolving lithospheric mantle in southern Africa, Geology, 36, 515-518, doi:10.1130/G24868A.1.

Kohlstedt, D. L., and S. J. Mackwell (1998), Diffusion of hydrogen and intrinsic point defects in olivine, Z. Phys. Chem., 207, 147-162.

Konrad-Schmolke, M., P. J. O'Brien, C. de Capitani, and D. A. Carswell (2008), Garnet growth at high- and ultra-high pressure conditions and the effect of element fractionation on mineral modes and composition, Lithos, 103, 309-332, doi:10.1016/j.lithos.2007.10.007.

Korja, T. (2007), How is the European lithosphere imaged by magnetotellurics?, Surv. Geophys., 28, 239-272, doi:10.1007/s10712-007-9024-9.

Kumar, P., X. Yuan, M. Ravi Kumar, R. Kind, X. Li, and R. Chadha (2007), The rapid drift of the Indian tectonic plate, Nature, 449, 894-897, doi:10.1038/nature06214.

Larson, A. M., J. A. Snoke, and D. E. James (2006), S-wave velocity structure, mantle xenoliths and the upper mantle beneath the Kaapvaal craton, Geophys. J. Int., 167, 171-186, doi:10.1111/j.1365-246X.2006.03005.x.

Lastovickova, M., and J. Buben (1975), The electrical conductivity of eclogites measured by two methods, Stud. Geophys. Geod., 19, 394-398, doi:10.1007/BF01615815.

Ledo, J., and A. G. Jones (2001), Regional electrical conductivity structure of the southern Canadian Cordillera and its physical interpretation, J. Geophys. Res., 106, 30,755-30,769, doi:10.1029/2001JB000358.

Ledo, J., P. Queralt, A. Marti, and A. G. Jones (2002), Two dimensional interpretation of 3-D magnetotelluric data: An example of limitations and resolution, Geophys. J. Int., 150, 127-139, doi:10.1046/j.1365246X.2002.01705.x.

Lee, C.-T., A. Lenardic, C. M. Cooper, F. Niu, and A. Levander (2005), The role of chemical boundary layers in regulating the thickness of continental and oceanic thermal boundary layers, Earth Planet. Sci. Lett., 230, 379-395, doi:10.1016/j.eps1.2004.11.019.

Li, A., and K. Burke (2006), Upper mantle structure of southern Africa from Rayleigh wave tomography, J. Geophys. Res., 111, B10303, doi:10.1029/2006JB004321.

McNeice, G. W., and A. G. Jones (2001), Multi-site, multi-frequency tensor decomposition of magnetotelluric data, Geophysics, 66, 158-173, doi:10.1190/1.1444891.

Mierdel, K., H. Keppler, J. R. Smyth, and F. Langenhorst (2007), Water solubility in aluminous orthopyroxene and the origin of Earth's asthenopshere, Science, 315, 364-368.

Moorkamp, M., A. G. Jones, and D. W. Eaton (2007), Joint inversion of teleseismic receiver functions and magnetotelluric data using a genetic algorithm: Are seismic velocities and electrical conductivities compatible?, Geophys. Res. Lett., 34, L16311, doi:10.1029/2007GL030519.

Moorkamp, M., A. G. Jones, and S. Fishwick (2010), Joint inversion of receiver functions, surface wave dispersion and magnetotelluric data, J. Geophys. Res., 115, B04318, doi:10.1029/2009JB006369.

Muller, M. R., et al. (2009), Lithospheric structure, evolution and diamond prospectivity of the Rehoboth Terrane and western Kaapvaal craton, southern Africa: Constraints from broadband magnetotellurics, Lithos, 112, suppl. 1, 93-105, doi:10.1016/j.lithos.2009.06.023.

Niblett, E. R., and C. Sayn-Wittgenstein (1960), Variation of the electrical conductivity with depth by the magnetotelluric method, Geophysics, 25 , 998-1008, doi:10.1190/1.1438799.

Niu, F., A. Levander, C. M. Cooper, C.-T. A. Lee, A. Lenardic, and D. E. James (2004), Seismic constraints on the depth and composition of the mantle keel beneath the Kaapvaal craton, Earth Planet. Sci. Lett., 224, 337-346, doi:10.1016/j.epsl.2004.05.011. 
Peslier, A. H., A. B. Woodland, D. R. Bell, and M. Lazarov (2010), Olivine water contents in the continental lithosphere and the longevity of cratons, Nature, 467, 78-81, doi:10.1038/nature09317.

Poe, B. T., C. Romano, F. Nestola, and J. R. Smyth (2010), Electrical conductivity anisotropy of dry and hydrous olivine at $8 \mathrm{GPa}$, Phys. Earth Planet. Inter., 181, 103-111, doi:10.1016/j.pepi.2010.05.003.

Richardson, S. H., J. J. Gurney, A. J. Erlank, and J. W. Harris (1984), Origin of diamonds in old enriched mantle, Nature, 310, 198-202, doi:10.1038/ $310198 \mathrm{a} 0$.

Richardson, S. H., S. B. Shirey, J. W. Harris, and R. W. Carlson (2001), Archean subduction recorded by Re-Os isotopes in eclogitic sulphide inclusions in Kimberly diamonds, Earth Planet. Sci. Lett., 191, 257-266, doi:10.1016/S0012-821X(01)00419-8.

Rodi, W., and R. L. Mackie (2001), Nonlinear conjugate gradients algorithm for 2-D magnetotelluric inversion, Geophysics, 66, 174-187, doi:10.1190/1.1444893.

Romano, C., B. Poe, N. Kreidie, and C. MacCammon (2006), Electrical conductivities of pyrope-almandine garnets up to $19 \mathrm{GPa}$ and $1700^{\circ} \mathrm{C}$, Am. Mineral., 91, 1371-1377, doi:10.2138/am.2006.1983.

Rudnick, R. L., and A. Nyblade (1999), The thickness and heat production of Archean lithosphere: Constraints from xenolith thermobarometry and surface heat flow, in Mantle Petrology: Field Observations and High Pressure Experimentation-A Tribute to F. R. Boyd, Spec. Publ., vol. 6 , edited by Y. Fei, C. M. Bertka, and B. O. Mysen, pp. 3-12, Geochem. Soc., St. Louis, Mo.

Rychert, C., and P. Shearer (2009), A global view of the lithosphereasthenosphere boundary, Science, 324, 495-498, doi:10.1126/science. 1169754 .

Saltzer, R. L., N. Chatterjee, and T. L. Grove (2001), The spatial distribution of garnets and pyroxenes in mantle peridotites: Pressure-temperature history of peridotites from the Kaapvaal craton, J. Petrol., 42, 2215-2229, doi:10.1093/petrology/42.12.2215.

Schwalenberg, K., V. Rath, and V. Haak (2002), Sensitivity studies applied to a two-dimensional resistivity model from the central Andes, Geophys. J. Int., 150, 673-686, doi:10.1046/j.1365-246X.2002.01734.x.

Shirey, S. B., J. W. Harris, S. H. Richardson, M. J. Fouch, D. E. James, P. Cartigny, P. Dienes, and F. Viljoen (2002), Diamond genesis, seismic structure, and evolution of the Kaapvaal-Zimbabwe craton, Science, 297, 1683-1686, doi:10.1126/science.1072384.

Shirey, S. B., S. H. Richardson, and J. W. Harris (2004), Integrated models of diamond formation and craton evolution, Lithos, 77, 923-944, doi:10.1016/j.lithos.2004.04.018.

Silver, P. G., M. J. Fouch, S. S. Gao, M. Schmitz, and the Kaapvaal Seismic Group (2004), Seismic anisotropy, mantle fabric and the magmatic evolution of Precambrian southern Africa, S. Afr. J. Geol., 107, 45-58, doi:10.2113/107.1-2.45

Silver, P. G., M. D. Behn, K. Kelley, M. Schmitz, and B. Savage (2006), Understanding cratonic flood basalts, Earth Planet. Sci. Lett., 245 , 190-201, doi:10.1016/j.epsl.2006.01.050.

Smith, D., and F. R. Boyd (1989), Compositional heterogeneities in minerals of sheared lherzolite inclusions from African kimberlites, Geol. Soc. Aust. Spec. Publ., 14, 709-724.

Solon, K., et al. (2005), Structure of the crust in the vicinity of the Banggong-Nujiang suture, central Tibet from INDEPTH magnetotelluric data, J. Geophys. Res., 110, B10102, doi:10.1029/2003JB002405.

Spratt, J. E., A. G. Jones, V. A. Jackson, L. Collins, and A. Avdeeva (2009), Lithospheric geometry of the Wopmay orogen from a Slave craton to Bear Province magnetotelluric transect, J. Geophys. Res., 114, B01101, doi:10.1029/2007JB005326.

Tinker, J. H., M. J. de Wit, and L. H. Royden (2004), Old, strong continental lithosphere with weak Archaean margin at $\sim 1.8 \mathrm{Ga}$, Kaapvaal craton, South Africa, S. Afr. J. Geol., 107, 255-260, doi:10.2113/107.1-2.255.

Tozer, D. C. (1979), The interpretation of upper-mantle electrical conductivities, Tectonophysics, 56, 147-163, doi:10.1016/0040-1951(79)90029-5.
Tozer, D. C. (1981), The mechanical and electrical properties of the Earth's asthenosphere, Phys. Earth Planet. Inter., 25, 280-296, doi:10.1016/ 0031-9201(81)90072-8.

Von Gruenewaldt, G., M. R. Sharpe, and C. J. Hatton (1985), The Bushveld Complex: Introduction and review, Econ. Geol., 80, 803-812, doi:10.2113/gsecongeo.80.4.803

Vozoff, K. (Ed.) (1986), Magnetotelluric Methods, Geophys. Reprint Ser., vol. 5, Soc. of Explor. Geophys., Tulsa, Okla.

Wang, D., M. Mookherjee, Y. Xu, and S. Karato (2006), The effect of water on the electrical conductivity of olivine, Nature, 443, 977-980, doi: $10.1038 /$ nature 05256 .

Wannamaker, P. E., G. W. Hohmann, and S. H. Ward (1984), Magnetotelluric responses of three-dimensional bodies in layered earths, Geophysics, 49, 1517-1533, doi:10.1190/1.1441777.

Webb, S. J. (2009) Southern African tectonics from potential field interpretation, Ph.D. thesis, Univ. of the Witwatersrand, Johannesburg, South Africa.

White, R. S., and D. McKenzie (1995), Mantle plumes and flood basalts, J. Geophys. Res., 100, 17,543-17,585, doi:10.1029/95JB01585.

Wittlinger, G., and V. Farra (2007), Converted waves reveal a thick and layered tectosphere beneath the Kalahari super-craton, Earth Planet. Sci. Lett., 254, 404-415, doi:10.1016/j.epsl.2006.11.048.

$\mathrm{Xu}$, Y. S., T. J. Shankland, and B. T. Poe (2000), Laboratory-based electrical conductivity in the Earth's mantle, J. Geophys. Res., 105, 27,865-27,875, doi:10.1029/2000JB900299.

Yang, Y., A. Li, and M. Ritzwoller (2008), Crustal and uppermost mantle structure in southern Africa revealed from ambient noise and teleseismic tomography, Geophys. J. Int., 174, 235-248, doi:10.1111/j.1365-246X. 2008.03779.x

Yoshino, T., and T. Katsura (2009), Reply to comments on "Electrical conductivity of wadsleyite as a function of temperature and water content" by Manthilake et al., Phys. Earth Planet. Inter., 174, 22-23, doi:10.1016/j. pepi.2009.01.012

Yoshino, T., T. Matsuzaki, S. Yamashita, and T. Katsura (2006), Hydrous olivine unable to account for conductivity anomaly at the top of the asthenosphere, Nature, 443, 973-976, doi:10.1038/nature05223.

Yoshino, T., T. Matsuzaki, A. Shatskiy, and T. Katsura (2009), The effect of water on the electrical conductivity of olivine aggregates and its implications for the electrical structure of the upper mantle, Earth Planet. Sci. Lett., 288, 291-300, doi:10.1016/j.epsl.2009.09.032.

Zhang, M., S. O'Reilly, K.-L. Wang, J. Hronsky, and W. Griffin (2008), Flood basalts and metallogeny: The lithospheric mantle connection, Earth Sci. Rev., 86, 145-174, doi:10.1016/j.earscirev.2007.08.007.

R. L. Evans, Department of Geology and Geophysics, Woods Hole Oceanographic Institution, 266 Woods Hole Rd., Clark 263, Woods Hole, MA 02543, USA. (revans@whoi.edu)

S. Evans, Moombarriga Geoscience, Box 1184, West Perth, WA 6872 , Australia.

C. J. S. Fourie, Environmental, Water and Earth Science Department, Tshwane University of Technology, Private Bag X 680, Pretoria, South Africa. (fouriecjs@tut.ac.za)

X. Garcia, Barcelona Center for Subsurface Imaging, Unitat de Tecnologia Marina, Pg. Maritim de la Barceloneta 37-49, E-08003 Barcelona, Spain. M. Hamilton, EMGS, Stiklestadveien 1, N-7041 Trondheim, Norway.

D. Hutchins, Geological Survey of Namibia, 1 Aviation Rd., Private Bag 13297, Windhoek, Namibia.

H. Jelsma, De Beers Group Services, Private Bag X01, Southdale 2135, South Africa.

A. G. Jones and M. Muller, Dublin Institute for Advanced Studies, 5 Merrion Square, Dublin 2, Ireland.

J. Spratt, Natural Resources Canada, 580 Booth, Ottawa, ON K1A 0E4, Canada.

S. Webb, School of Geosciences, University of Witwatersrand, Wits 2050, South Africa. 